\title{
Enantiomeric Trimethylallantoin Monomers, Dimers, and Trimethyltriuret: Evidence for an Alternative Catabolic Pathway of Caffeine in Tea Plant
}

Wei Wang ${ }^{1}$, Bi-Ying Zhu' ${ }^{1}$, Pu Wang ${ }^{2}$, Peng Zhang ${ }^{1}$, Wei-Wei Deng ${ }^{1}$, Fei-Hua $\mathrm{Wu}^{2}$, Chi-Tang $\mathrm{Ho}^{1,3}$, Tie-Jun Ling ${ }^{1}$, Zheng-Zhu Zhang ${ }^{1}$, Xiao-Chun Wan ${ }^{1}$, Guan-Hu Bao ${ }^{1, *}$

${ }^{1}$ Natural Products Laboratory, International Joint Laboratory of Tea Chemistry and Health Effects, State Key Laboratory of Tea Plant Biology and Utilization, Anhui Agricultural University, Hefei, 230036, China

${ }^{2}$ School of Traditional Chinese Pharmacy, China Pharmaceutical University, Nanjing 211198, China

${ }^{3}$ Department of Food Science, Rutgers University, New Brunswick, New Jersey 08901-8520, USA

Supporting Information

\section{Contents of Supporting Information}

1. Experimental section .3

1.1. General experimental procedures .3

1.2. Chemicals and plant materials .4

1.3. Extraction and isolation 4

1.4. Physical and chemical properties of conpounds 1-4 .5

1.5. Protective effects against high glucose induced cellular senescence in human umbilical vein endothelial cells assay. . .6

1.6. $1,3-{ }^{15} \mathrm{~N}_{2}$-caffeine Stable isotope tracer experiment .7

1.7. UPLC-TOF-MS analyses of the extracts of the fresh leaves and the processed materials of Keemun black tea. .8

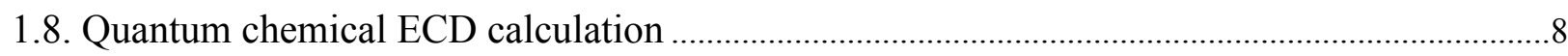

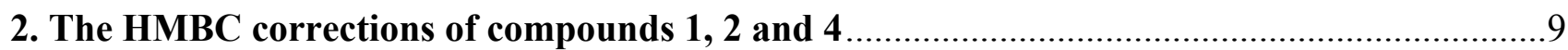

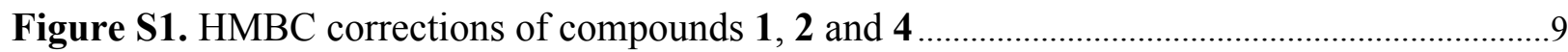




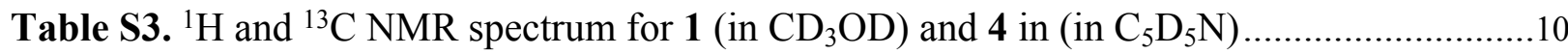

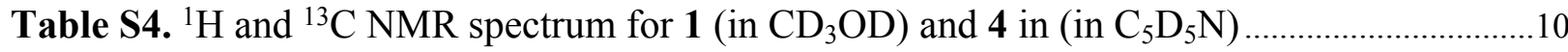

4. Protective effects against high glucose induced cellular senescence in human umbilical vein endothelial cells .10

Figure S2. Compounds 1a, 1b and 3 protect high glucose induced cell senescence of HUVECs

Figure S3. HR-ESI-MS spectrum of 1

Figure S4. UV spectrum of 1

Figure S5. ${ }^{1} \mathrm{H}$ NMR spectrum of 1 in $\mathrm{CD}_{3} \mathrm{OD}$ .11

Figure S6. ${ }^{13} \mathrm{C}$ NMR spectrum of $\mathbf{1}$ in $\mathrm{CD}_{3} \mathrm{OD}$

Figure S7. HMQC spectrum of 1

Figure S8. HMBC spectrum of $\mathbf{1}$

Figure S9. HR-ESI-MS spectrum of 2

Figure S10. UV spectrum of 2

Figure S11. ${ }^{1} \mathrm{H}$ NMR spectrum of 2 in $\mathrm{CD}_{3} \mathrm{OD}$

Figure S12. ${ }^{13} \mathrm{C}$ NMR 2 in $\mathrm{CD}_{3} \mathrm{OD}$

Figure S13. HSQC spectrum of 2

Figure S14. HMBC spectrum of 2

Figure S15. HR-ESI-MS spectrum of 3 .16

Figure S16. UV spectrum of $\mathbf{3}$ 16

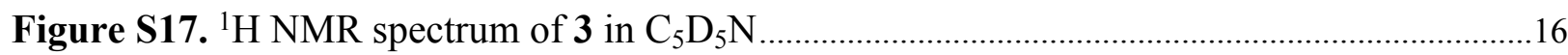

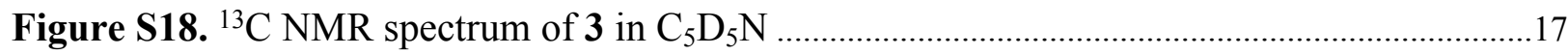

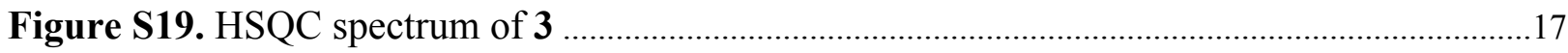

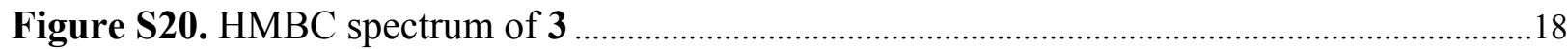

Figure S21. HR-ESI-MS spectrum of 4 .18 
Figure S22. UV spectrum of 4 .

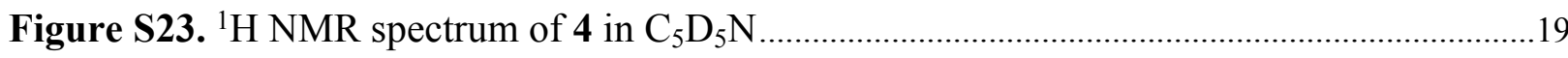

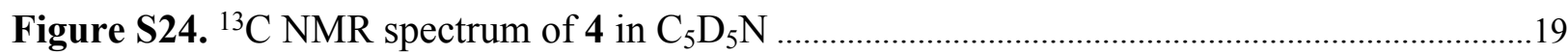

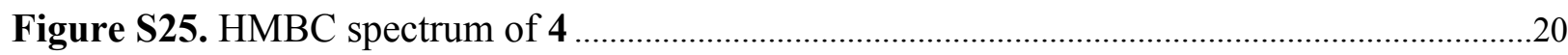

6. Chiral separation of compounds 1 and 3, separation of compound 2 and 4 by HPLC and

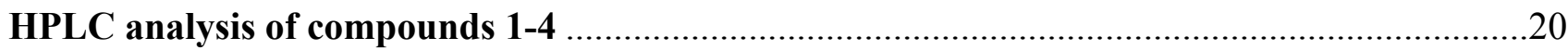

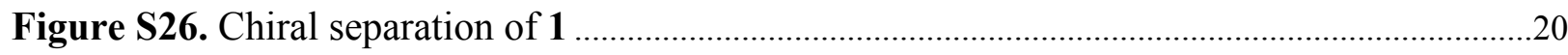

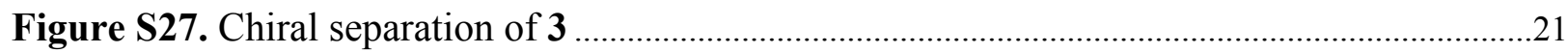

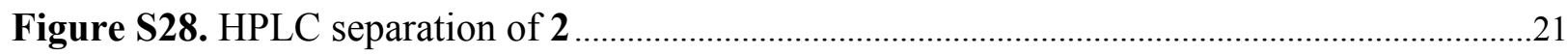

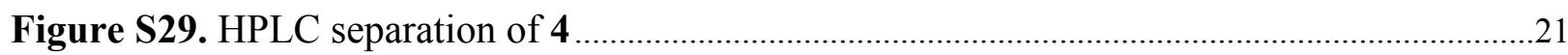

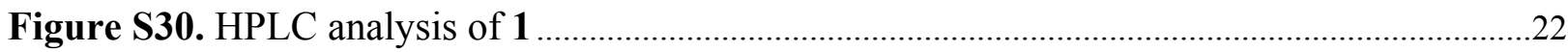

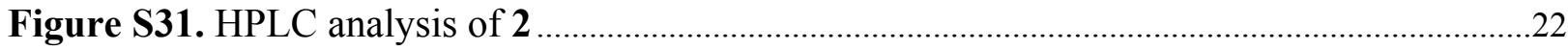

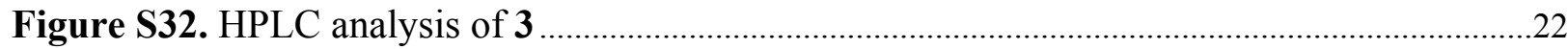

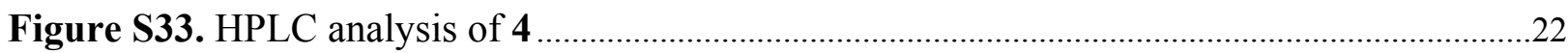

7. UPLC-TOF-MS analyses of the extracts of the fresh leaves and the processed materials of

Keemun black tea

Figure S34. UPLC-TOF-MS analysis of 1 in fresh leaves and the processed materials of Keemun black tea . .23

Figure S35. UPLC-TOF-MS analysis of 4 in fresh leaves and the processed materials of Keemun black tea. 24

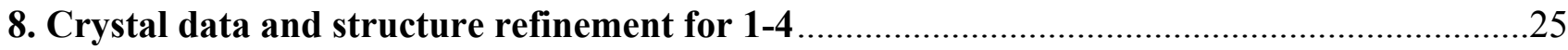

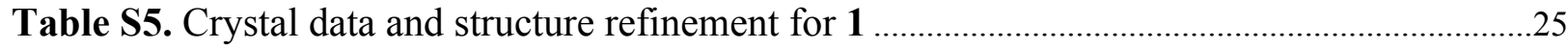

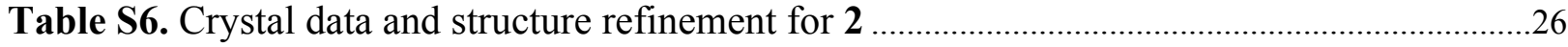

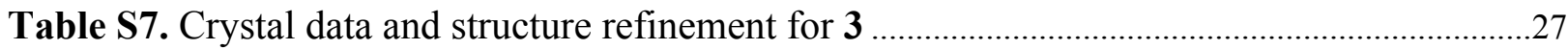

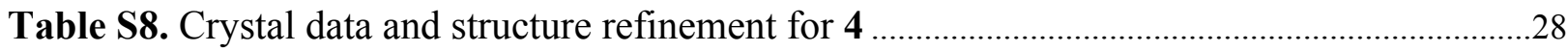

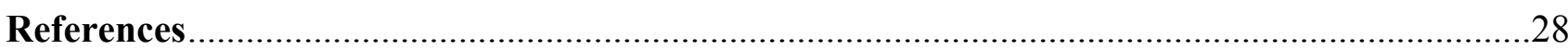




\section{Experimental section}

\subsection{General experimental procedures}

The NMR spectra were recorded in $\mathrm{CD}_{3} \mathrm{OD}$ and $\mathrm{C}_{5} \mathrm{D}_{5} \mathrm{~N}$ with the Agilent DD2 (600 MHz for ${ }^{1} \mathrm{H}$ and $125 \mathrm{MHz}$ for ${ }^{13} \mathrm{C}$ ), respectively. HR-ESI-MS were detected on the Agilent $1290 \mathrm{UPLC} /$ time-of-flight (TOF, 6545) MS system by the positive-ion mode. Optical roation $(\alpha)$ was detected with a MCP 100 Modular Circular Polarimeter (Anton Paar, Germany). Circular dichroism (CD) spetra was detected with a JASCO J-815 spectropolarimeter (JASCO, Tokyo, Japan). Melting points were detected with an X-4 micro melting point apparatus (Jing Song, Shanghai, China). HPLC analysis was performed on a Waters 2695 separation module combined with a 2998 PDA detector (Waters, USA). Silica gel of 100-200 and 300-400 mesh (Qingdao Marine Chemical Factory in China), ODS (FUJI SILYSIA CHEMICAL LTD., Japan), Toyopearl HW-40F (TOSOH BIOSCIENCE SHANGHAI CO., LTD., China) were applied to isolate and purify compounds. The silica gel GF254 plates (made in Yantai, China) were tested and colorated with bismuth potassium iodide solution.

\subsection{Chemicals and plant materials}

Keemun black tea for phytochemical research was purchased from Qimen, Anhui province, China, in 2012. Acetonitrile and water of UPLC grade were purchased from Fisher (Fair Lawn, US), Acetonitrile and methanol of HPLC grade for HPLC assay were purchased from DUKSAN, Korea. ${ }^{15} \mathrm{~N}$-Caffeine $\left(1,3-{ }^{15} \mathrm{~N}_{2}, 99 \%\right)$ was purchased from CIL (Cambridge Isotope Laboratories, Inc.). D-caffeine (trimethyl- $\mathrm{d}_{9}, 99 \%$ ) and Caffeine (98\%) were purchased from Sigma. ${ }^{13} \mathrm{C}$-caffeine (trimethyl- ${ }^{13} \mathrm{C}_{3}, 97 \%$ ) was purchased from TRC (Toronto Research Chemicals, Inc.). And all of the following reagents used for extraction and isolation were analytical grade from China: petroleum ether, dichloromethane, ethyl acetate, n-butanol, methanol.

\subsection{Extraction and isolation}

Keemun black tea extract was separated by a silica gel column chromatography (CC) to afford eighteen fractions (A1-A18) as repoted. ${ }^{1}$ Fraction A12 was subjected to a silica gel CC eluted with dichloromethane-methanol (1000:1 to $1: 1, \mathrm{v} / \mathrm{v})$ to yield six subfractions (A12-a to A12-f). Subfraction A12-d was recrystallized to yield 3 (10.0 mg). Subsequently, 3 was separated by HPLC 
using a chiral column to obtain two enantiomers, $\mathbf{3 a}(2.5 \mathrm{mg})$ and $\mathbf{3 b}(2.6 \mathrm{mg})$. The residue was subjected to a Toyopearl HW-40F CC eluted with methanol to afford 2 fractions (A12-d1and A12-d2). Fraction A12-d1 was subjected to HPLC to yeild 2 (6.0 mg). Fraction A12-d2 was subjected to a silica gel CC eluted with ethyl acetate-methanol $(50: 1, \mathrm{v} / \mathrm{v})$ to yield 1 (57.5 $\mathrm{mg})$. Subsequently, 1 (15.8 mg) was separated by HPLC using a chiral column to obtain two enantiomers, $1 \mathrm{a}(7.4 \mathrm{mg})$ and $1 \mathrm{~b}(7.5 \mathrm{mg})$. Fraction A8 was subjected to a silica gel CC eluted with ethyl acetate-acetone (20:1 to $1: 1, \mathrm{v} / \mathrm{v})$ to yield ten fractions (A13-a to A13-j). Fraction A13-c was subjected to a silica gel CC eluted with ethyl acetate-acetone (90:1 to 70:1, v/v) and HPLC to yield 4 (6.5 mg).

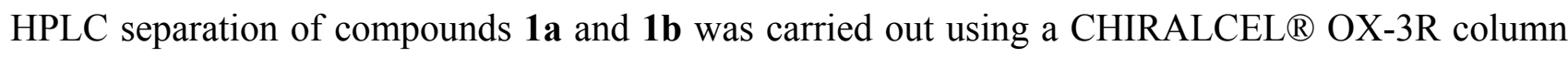
(4.6 $\mathrm{mm} \phi \times 150 \mathrm{mmL}, 3 \mu \mathrm{m})$ using acetonitrile as the eluent and performed at a solvent flow rate of $0.3 \mathrm{~mL} / \mathrm{min}$ (Figure S27). The injection volume was $15 \mu \mathrm{L}$. Column temperature was set at $28^{\circ} \mathrm{C}$. The UV detection wavelength was monitored at $220 \mathrm{~nm}$ during the HPLC separation.

HPLC separation of compound 2 was carried out using a semi-preparative X Bridge Prep C18 column $(10 \mathrm{~mm} \times 250 \mathrm{~mm}, 5 \mu \mathrm{m})$ using $14 \%$ acetonitrile solution as the eluent and performed at a solvent flow rate of $2.0 \mathrm{~mL} / \mathrm{min}$ (Figure S29). Column temperature was set at $30{ }^{\circ} \mathrm{C}$. The injection volume was $50 \mu \mathrm{L}$. The UV detection wavelength was monitored at $210 \mathrm{~nm}$.

HPLC separation of compounds $\mathbf{3 a}$ and $\mathbf{3 b}$ was carried out using a CHIRALCEL $®$ OX-3R column (4.6 $\mathrm{mm} \phi \times 150 \mathrm{mmL}, 3 \mu \mathrm{m})$ using acetonitrile as the eluent and performed at a solvent flow rate of $0.3 \mathrm{~mL} / \mathrm{min}$ (Figure S28). The injection volume was $15 \mu \mathrm{L}$. Column temperature was set at $25{ }^{\circ} \mathrm{C}$. The UV detection wavelength was monitored at $220 \mathrm{~nm}$ during the HPLC separation.

HPLC separation of compound 4 was carried out using an SP ODS-A C18 column $(4.6 \mathrm{~mm} \times 250$ mm i.d., $5 \mu \mathrm{m}$ ) using $8 \%$ acetonitrile solution as the eluent and performed at a solvent flow rate of $1.0 \mathrm{~mL} / \mathrm{min}$ (Figure S30). Column temperature was set at $30{ }^{\circ} \mathrm{C}$. The injection volume was $20 \mu \mathrm{L}$. The UV detection wavelength was monitored at $210 \mathrm{~nm}$.

\subsection{Physical and chemical properties of compounds 1-4}

( \pm ) 1,3,8-Trimethylallantoin (1): Colorless powder, m.p. 158-159; [ $\alpha 25 \mathrm{D} \pm 0^{\circ}$ (c $\left.0.7 \mathrm{MeOH}\right)$; 
HR-ESI-MS at $m / z 223.0808[\mathrm{M}+\mathrm{Na}]^{+}$(calcd for $\mathrm{C}_{7} \mathrm{H}_{12} \mathrm{~N}_{4} \mathrm{O}_{3} \mathrm{Na}, 223.0807$ ). ${ }^{1} \mathrm{H}$ and ${ }^{13} \mathrm{C}$ NMR data see Table S3.

$S$-(+)-1,3,8-Trimethylallantoin (1a): Colorless powder; $\left.[\alpha] 25 \mathrm{D}+60.8^{\circ}(c) 0.7 \mathrm{MeOH}\right) ; \mathrm{CD}$ $(\mathrm{MeOH}) \lambda(\Delta \varepsilon) 218(+16.1), 242(-2.3)$.

$R$-(-)-1,3,8-Trimethylallantoin (1b): Colorless powder; $\left.[\alpha] 25 \mathrm{D}-61.3^{\circ}(c) 0.7 \mathrm{MeOH}\right) ; \mathrm{CD}$ $(\mathrm{MeOH}) \lambda(\Delta \varepsilon) 218(-17.1), 242(+2.3)$.

1,3,8-Trimethylallantoin 4R,4'S-dimer (2): Colorless powder, m.p. $214-215{ }^{\circ} \mathrm{C} ;[\alpha] 25 \mathrm{D} \pm 0^{\circ}(c 0.3$ $\mathrm{MeOH}) ; \mathrm{HR}-\mathrm{ESI}-\mathrm{MS}$ at $\mathrm{m} / z 421.1560[\mathrm{M}+\mathrm{Na}]^{+}\left(\mathrm{Calcd}\right.$ for $\left.\mathrm{C}_{14} \mathrm{H}_{22} \mathrm{~N}_{8} \mathrm{O}_{6} \mathrm{Na}, 421.1560\right), 819.3201$ $[2 \mathrm{M}+\mathrm{Na}]^{+}$(calcd for $\left.\mathrm{C}_{28} \mathrm{H}_{44} \mathrm{~N}_{16} \mathrm{O}_{12} \mathrm{Na}, 819.3222\right) .{ }^{1} \mathrm{H}$ and ${ }^{13} \mathrm{C}$ NMR data see Table $\mathrm{S} 4$.

1,3,8-Trimethylallantoin 4,4'-dimer (3): Colorless powder, $[\alpha] 25 \mathrm{D} \pm 0^{\circ}(c \quad 0.7 \mathrm{MeOH})$; HR-ESI-MS at $m / z 421.1560[\mathrm{M}+\mathrm{Na}]^{+}\left(\mathrm{Calcd}\right.$ for $\left.\mathrm{C}_{14} \mathrm{H}_{22} \mathrm{~N}_{8} \mathrm{O}_{6} \mathrm{Na}, 421.1560\right), 819.3233$ [2M+Na] $]^{+}$ (calcd for $\mathrm{C}_{28} \mathrm{H}_{44} \mathrm{~N}_{16} \mathrm{O}_{12} \mathrm{Na}, 819.3222$ ). ${ }^{1} \mathrm{H}$ and ${ }^{13} \mathrm{C}$ NMR data see Table S4.

1,3,8-Trimethylallantoin $4 S, 4$ 'S-dimer (3a): Colorless powder, m.p. $196-197{ }^{\circ} \mathrm{C} ;[\alpha] 25 \mathrm{D}+32^{\circ}(c$ $0.3 \mathrm{MeOH}) ; \mathrm{CD}(\mathrm{MeOH}) \lambda(\Delta \varepsilon) 220(+23.6), 245(-11.3)$.

1,3,8-Trimethylallantoin $4 R, 4^{\prime} R$-dimer (3b): Colorless powder, m.p. $192-193{ }^{\circ} \mathrm{C} ;[\alpha] 25 \mathrm{D}-28^{\circ}(c$ $0.3 \mathrm{MeOH}) ; \mathrm{CD}(\mathrm{MeOH}) \lambda(\Delta \varepsilon) 220(-21.8), 245(+10.6)$.

1,3,7-Trimethyltriuret (4): Colorless powder, m.p. $185-186{ }^{\circ} \mathrm{C}$; HR-ESI-MS at $\mathrm{m} / \mathrm{z} 211.0806$ $[\mathrm{M}+\mathrm{Na}]^{+}$(calcd for $\mathrm{C}_{6} \mathrm{H}_{12} \mathrm{~N}_{4} \mathrm{O}_{3} \mathrm{Na}, 211.0807$ ), $399.1706[2 \mathrm{M}+\mathrm{Na}]^{+}$(calcd for $\mathrm{C}_{12} \mathrm{H}_{24} \mathrm{~N}_{8} \mathrm{O}_{6} \mathrm{Na}$, 399.1717). ${ }^{1} \mathrm{H}$ and ${ }^{13} \mathrm{C}$ NMR data see Table S3.

1.5. Protective effects against high glucose induced cellular senescence in human umbilical vein endothelial cells assay.

The human umbilical vein endothelial cells (HUVECs, obtained from Shanghai Honsun Biological Technology Co., Ltd., China) were cultured in Dulbecco's modified Eagle's medium (DMEM) supplemented with $10 \%$ fetal bovine serum (FBS), $125 \mu \mathrm{g} / \mathrm{mL}$ penicillin and $75 \mu \mathrm{g} / \mathrm{mL}$ streptomycin in a humidified $5 \% \mathrm{CO}_{2}$ atmosphere at $37{ }^{\circ} \mathrm{C}$. Media were changed every day. HUVECs were seeded in 6-well plates and cultured $24 \mathrm{~h}$. Subsequently, HUVECs were treated with or without 10 $\mu \mathrm{M}$ compounds, and then incubated with $33 \mathrm{mM}$ glucose for $48 \mathrm{~h}$. 
Activity of $\beta$-galactosidase was determined using the Senescence Detection Kit (Beyotime, Shanghai, China). The percentage of $\beta$-galactosidase-positive cells in the total cell population were determined by counting six random fields. All images were obtained using a fluorescence microscope (Olympus, IX51S8F-3, Japan). Metformin was used as the positive control. Results are expressed as the mean \pm SEM.

\section{6. ${ }^{15} \mathrm{~N}$-caffeine, ${ }^{13} \mathrm{C}$-caffeine and D-caffeine stable isotope tracer experiments}

The stable isotope tracer experiments were carried out as specified by Ito and Ashihara with a slight modification ${ }^{2}$. The segments of leaves $(100 \mathrm{mg})$ obtained tea seedlings were placed in flasks with 2 $\mathrm{mL}$ of $30 \mathrm{mM}$ K-Pi buffer (pH 5.6) containing $20 \mathrm{mM}$ sucrose, $1 \% \mathrm{Na}$ ascorbate, and ${ }^{15} \mathrm{~N}$-labelled caffeine $(30 \mathrm{mM})$ or ${ }^{13} \mathrm{C}$-labelled caffeine $(30 \mathrm{mM})$ or D-labelled caffeine $(30 \mathrm{mM})$. For comparison, the metabolisms of caffeine $(30 \mathrm{mM}$, without labeled) and $0 \mathrm{mM}$ caffeine in the leaves of tea and cucumber were performed as controls. The flasks were incubated in an incubator at $28{ }^{\circ} \mathrm{C}$ for $24 \mathrm{~h}$ at $160 \mathrm{rpm}$. For analysis of labeled-metabolites, samples were homogenized using a mortar and pestle with 70\% methanol aqueous. The extracts were applied to UPLC-TOF-MS and UPLC-Orbitrap-MS. The UPLC-TOF-MS parameters were as follows. Column temperature was set at $30^{\circ} \mathrm{C}$. The eluent was composed of mobile phase A $(0.1 \%$ formic acid in water $)$ and mobile phase $\mathrm{B}(0.1 \%$ formic acid in acetonitrile). The gradient of mobile phase B was as follows: 0-2 min, keep 6\%; 2-3.5 min, from $6 \%$ to $15 \% ; 3.5-5 \mathrm{~min}$, from $15 \%$ to $90 \%$; then keep $90 \%$ for $4 \mathrm{~min}$; $9-9.5 \mathrm{~min}$, from $95 \%$ to $6 \%$; then keep $6 \%$ for $2.5 \mathrm{~min}$. The injection volume was $2 \mu \mathrm{L}$, with a flow rate of $0.2 \mathrm{~mL} / \mathrm{min}$. It was carried out using an ACQUITY UPLC $®$ BEH Shield C18 column $(2.1 \times 50$ mm, i.d., $1.7 \mu \mathrm{m})$.

The UPLC-Orbitrap-MS parameters were as follows. Column temperature was set at $25{ }^{\circ} \mathrm{C}$. The eluent was composed of mobile phase A $(0.1 \%$ formic acid in water) and mobile phase B $(0.1 \%$ formic acid in acetonitrile). The gradient of mobile phase B was as follows: 0-2 min, keep 10\%; $2-2.5 \mathrm{~min}$, from $10 \%$ to $25 \%$; $2.5-4 \mathrm{~min}$, from $25 \%$ to $95 \%$; then keep $95 \%$ for $3 \mathrm{~min}$; $7-7.5 \mathrm{~min}$, from $95 \%$ to $10 \%$; then keep $10 \%$ for $2.5 \mathrm{~min}$. The injection volume was $3 \mu \mathrm{L}$, with a flow rate of $0.2 \mathrm{~mL} / \mathrm{min}$. It was carried out using an ACQUITY UPLC® BEH Shield C18 column $(2.1 \times 50 \mathrm{~mm}$, i.d., $1.7 \mu \mathrm{m})$. 
1.7. UPLC-TOF-MS analyses of the extracts of the fresh leaves and the processed materials of

\section{Keemun black tea.}

Preparation of samples solution: $1.00 \mathrm{~g}$ of ground tea samples for UPLC-TOF-MS experiment were extracted in $20 \mathrm{~mL} \mathrm{70 \%} \mathrm{methanol} \mathrm{aqueous} \mathrm{for} \mathrm{five} \mathrm{times} \mathrm{within} 12 \mathrm{~h}$ (30 min each time) by ultrasonic extraction. All of the extracion were diluted with water and extracted by dichloromethane, respectively. The dichloromethane solution was concentrated under reduced pressure to afford the crude extracts that were used for UPLC-TOF-MS analyses. The UPLC conditions were shown above.

\subsection{Quantum chemical ECD calculation}

In general, conformational analyses were carried out via random searching in the Sybyl-X 2.0 using the MMFF94S force field with an energy cutoff of $3.0 \mathrm{kcal} / \mathrm{mol}$. The results showed four lowest energy conformers for $S \mathbf{- 1}$. Subsequently, the conformers were re-optimized using DFT at the b3lyp/6-31+g(d) level in $\mathrm{MeOH}$ using the polarizable conductor calculation model (CPCM) by the GAUSSIAN 09 program. ${ }^{3}$ The energies, oscillator strengths, and rotational strengths (velocity) of the first 30 electronic excitations were calculated using the TDDFT methodology at the b3lyp/6-311++g(d,p) level in $\mathrm{MeOH}$. The ECD spectra were simulated by the overlapping Gaussian function (half the bandwidth at $1 / \mathrm{e}$ peak height, $\sigma=0.16) .{ }^{4}$ To get the final spectra, the simulated spectra of the conformers were averaged according to the Boltzmann distribution theory and their relative Gibbs free energy $(\Delta \mathrm{G})$, theoretical ECD spectrum of the corresponding enantiomer was obtained by directly inverse of the ECD spectrum of the calculated model molecule, respectively. By comparing the experiment spectrum with the calculated ECD spectra, the only chiral centre of 1a and $\mathbf{1 b}$ was determined to be $R$ and $S$, respectively.

Table S1. The optimized conformers of $S \mathbf{- 1}$.

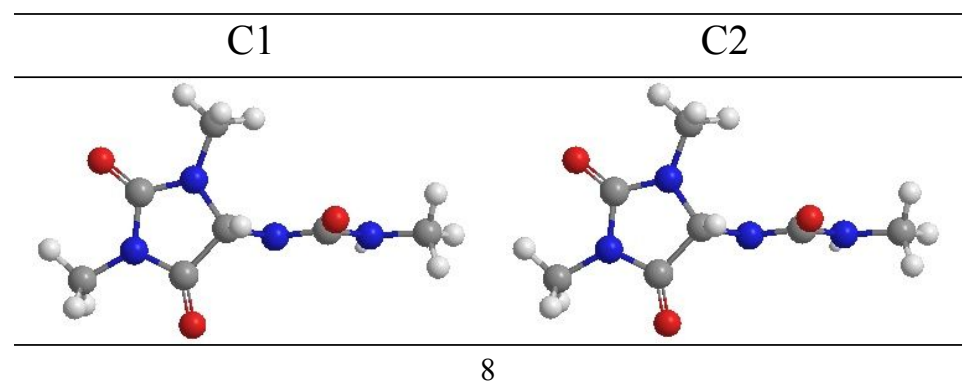




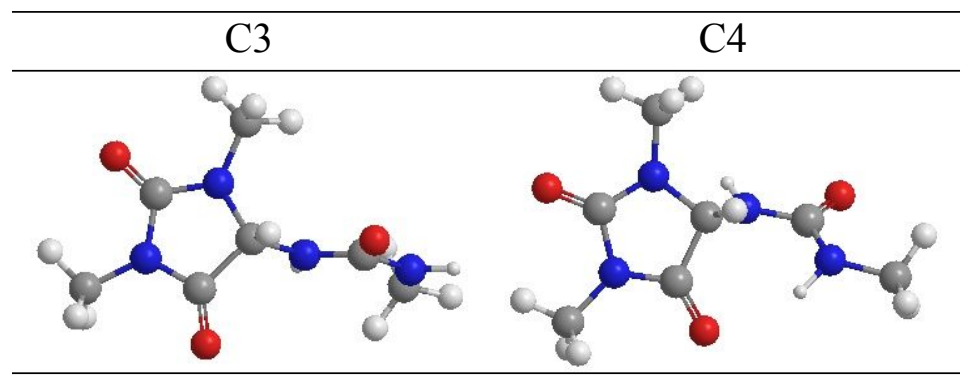

Table S2. B3LYP-calculated relative energies (Kcal/mol) and conformational population (\%) for the most stable conformers of $S$-1.

\begin{tabular}{ccrc}
\hline Comound & conformer & $\Delta \mathrm{E}(\mathrm{kcal} / \mathrm{mol})^{\mathrm{a}}$ & Population $(\%)^{\mathrm{b}}$ \\
\hline \multirow{3}{*}{1} & $\mathrm{C} 1$ & 0 & 42.17 \\
& $\mathrm{C} 2$ & 0.0000005 & 42.14 \\
& $\mathrm{C} 3$ & 0.0009562 & 15.30 \\
& $\mathrm{C} 4$ & 0.0044264 & 0.39
\end{tabular}

${ }^{a}$ Relative to conformer C1 with E6-31+G(d) $=-718.7835253 \mathrm{Kcal} / \mathrm{mol} .{ }^{b}$ Calculated using free energy values from Gaussian $03 \mathrm{~W}$ according to $\Delta \mathrm{G}=-\mathrm{RT}$ In $\mathrm{K}$.

\section{The HMBC corrections of compounds 1,2 and 4.}<smiles>O=C1CN2CC3CCCC(CC2=O)N3C(=O)NCCCN(CCO)CN1</smiles>

1

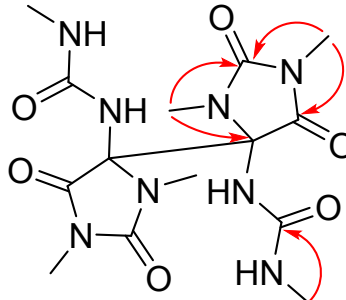

2<smiles>CNC(=O)N1C2CCCC1C(=O)NC(=O)NCC2</smiles>

4

Figure S1. HMBC corrections of compounds 1, 2 and 4. 


\section{3. ${ }^{1} \mathrm{H}$ and ${ }^{13} \mathrm{C}$ NMR spectral data for $1-4$.}

Table S3. ${ }^{1} \mathrm{H}(600 \mathrm{~Hz})$ and ${ }^{13} \mathrm{C}$ NMR $(150 \mathrm{~Hz})$ spectrum for $1\left(\right.$ in $\left.\mathrm{CD}_{3} \mathrm{OD}\right)$ and 4 in $\left(\right.$ in $\left.\mathrm{C}_{5} \mathrm{D}_{5} \mathrm{~N}\right)(\mathrm{s}$ : single peak; d: double peaks)

\begin{tabular}{cccccc}
\hline & \multicolumn{2}{c}{ Compound $\mathbf{1}$} & \multicolumn{3}{c}{ Compound $\mathbf{4}$} \\
\hline position & $\delta_{\mathrm{C}}$ & $\delta_{\mathrm{H}}(J$ in Hz$)$ & position & $\delta_{\mathrm{C}}$ & $\delta_{\mathrm{H}}(J$ in Hz$)$ \\
2 & 158.3 & & 2 & 157.7 & \\
4 & 67.5 & $5.18 \mathrm{~s}$ & 4 & 154.7 & \\
5 & 173.2 & & 6 & 154.2 & \\
7 & 160.3 & & 8 & 27.4 & $2.78 \mathrm{~d}(4.2)$ \\
9 & 25.0 & $2.98 \mathrm{~s}$ & 9 & 30.2 & $3.23 \mathrm{~s}$ \\
10 & 26.8 & $2.87 \mathrm{~s}$ & 10 & 26.4 & $2.86 \mathrm{~d}(4.8)$ \\
11 & 26.9 & $2.69 \mathrm{~s}$ & & & \\
\hline
\end{tabular}

Table S4. ${ }^{1} \mathrm{H}(600 \mathrm{~Hz})$ and ${ }^{13} \mathrm{C}$ NMR $(150 \mathrm{~Hz})$ spectrum for $2\left(\right.$ in $\left.\mathrm{CD}_{3} \mathrm{OD}\right)$ and 3 in $\left(\right.$ in $\left.\mathrm{C}_{5} \mathrm{D}_{5} \mathrm{~N}\right)$ (s: single peak; d: double peaks)

\begin{tabular}{|c|c|c|c|c|}
\hline \multicolumn{3}{|c|}{ Compound $\mathbf{2}$} & \multicolumn{2}{|c|}{ Compound $\mathbf{3}$} \\
\hline position & $\delta_{\mathrm{C}}$ & $\delta_{\mathrm{H}}(J$ in $\mathrm{Hz})$ & $\delta_{\mathrm{C}}$ & $\delta_{\mathrm{H}}(J$ in $\mathrm{Hz})$ \\
\hline $2,2^{\prime}$ & 159.2 & & 158.0 & \\
\hline $4,4^{\prime}$ & 77.7 & & 75.3 & \\
\hline $5,5^{\prime}$ & 172.0 & & 171.9 & \\
\hline $7,7^{\prime}$ & 158.9 & & 156.8 & \\
\hline $9,9^{\prime}$ & 25.2 & $2.97 \mathrm{~s}$ & 25.3 & $3.13 \mathrm{~s}$ \\
\hline $10,10^{\prime}$ & 26.6 & $2.88 \mathrm{~s}$ & 26.2 & $2.90 \mathrm{~s}$ \\
\hline $11,11^{\prime}$ & 27.1 & $2.65 \mathrm{~s}$ & 26.6 & $2.78 \mathrm{~d}(4.2)$ \\
\hline
\end{tabular}

4. Protective effects against high glucose induced cellular senescence in human umbilical vein endothelial cells.

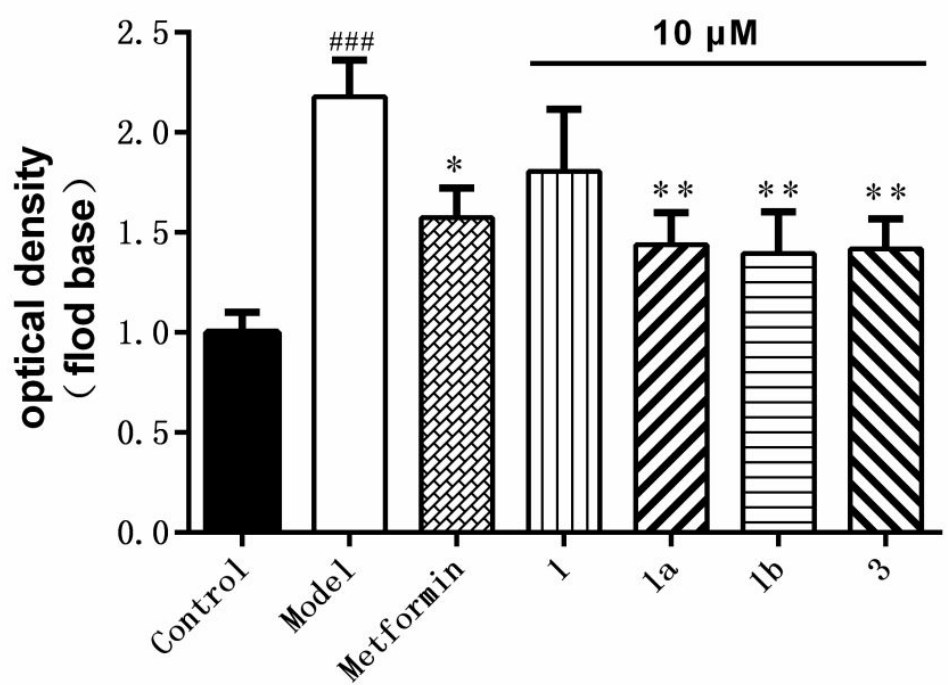

Figure S2. Compounds 1a, 1b and $\mathbf{3}$ protect high glucose induced cell senescence of HUVECs.

(These data are expressed as the mean $\pm \mathrm{SEM} ;{ }^{\# \#} \mathrm{p}<0.001$ compared with the control group, ${ }^{*} \mathrm{p}<$ 0.05 and $* * p<0.01$ compared with the model group.)

\section{HR-ESI-MS, UV and NMR spectra of 1-4.}




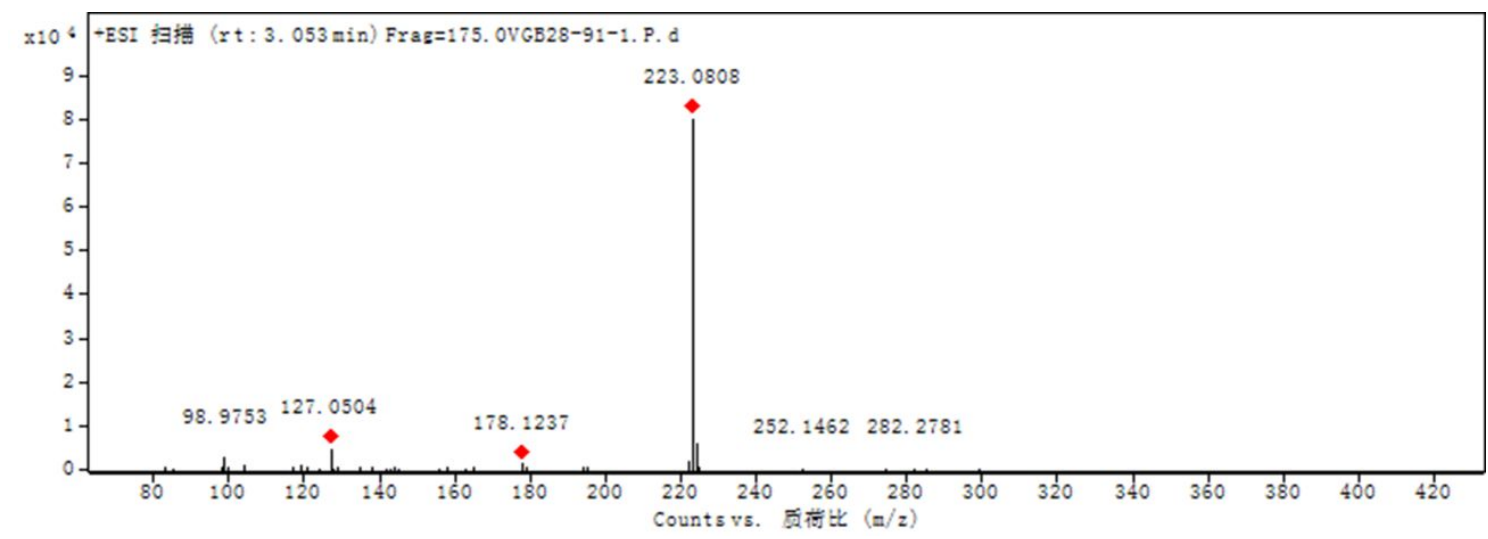

Figure S3. HR-ESI-MS spectrum of 1

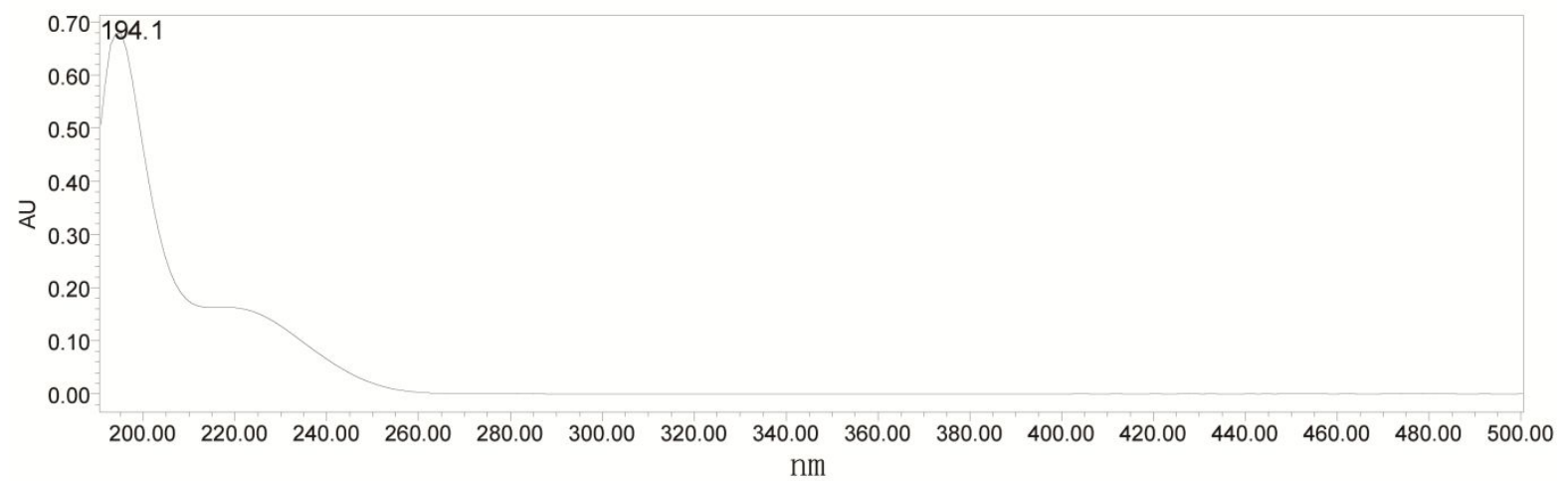

Figure S4. UV spectrum of 1

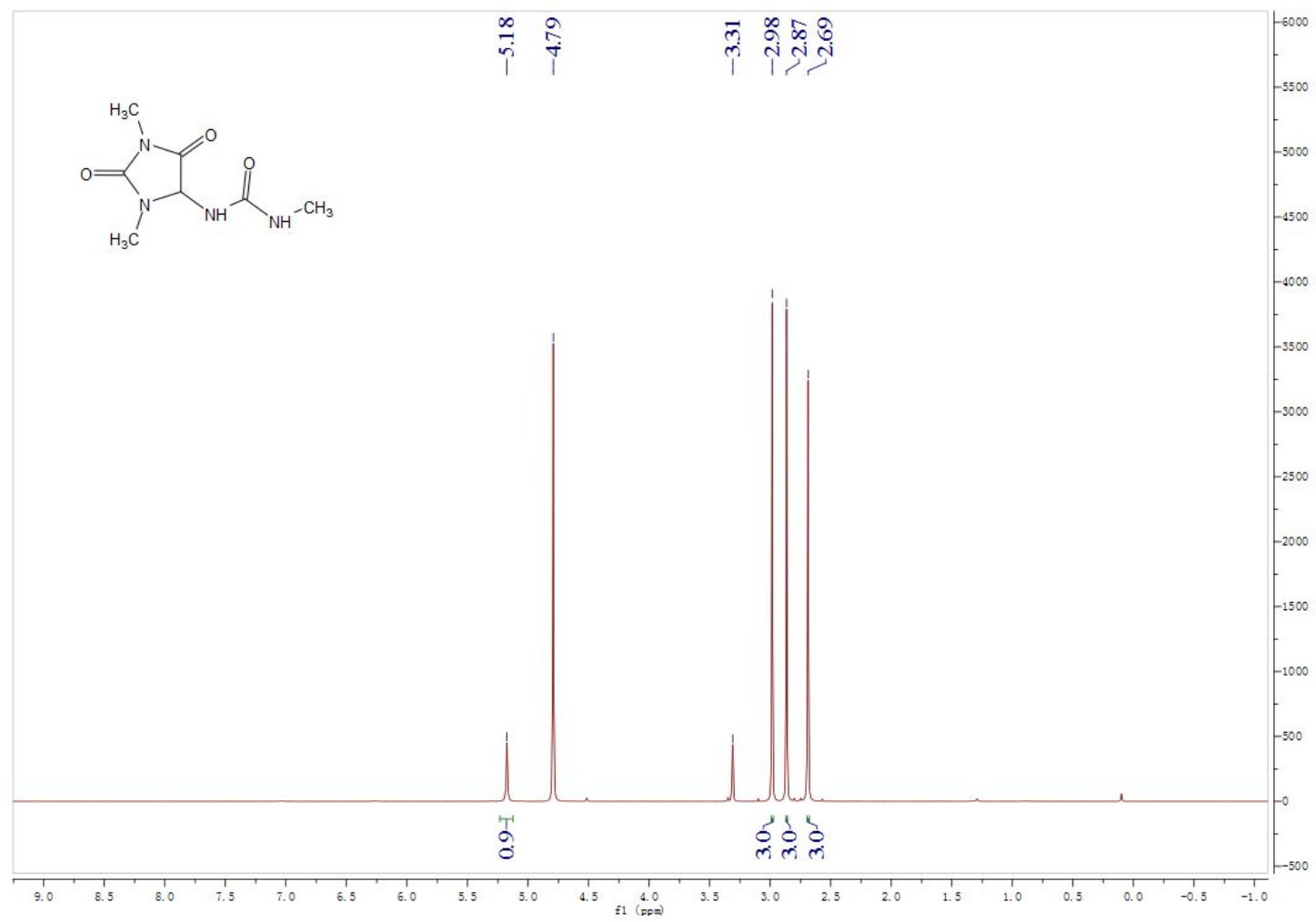

Figure S5. ${ }^{1} \mathrm{H}$ NMR spectrum of $\mathbf{1}$ in $\mathrm{CD}_{3} \mathrm{OD}$ 


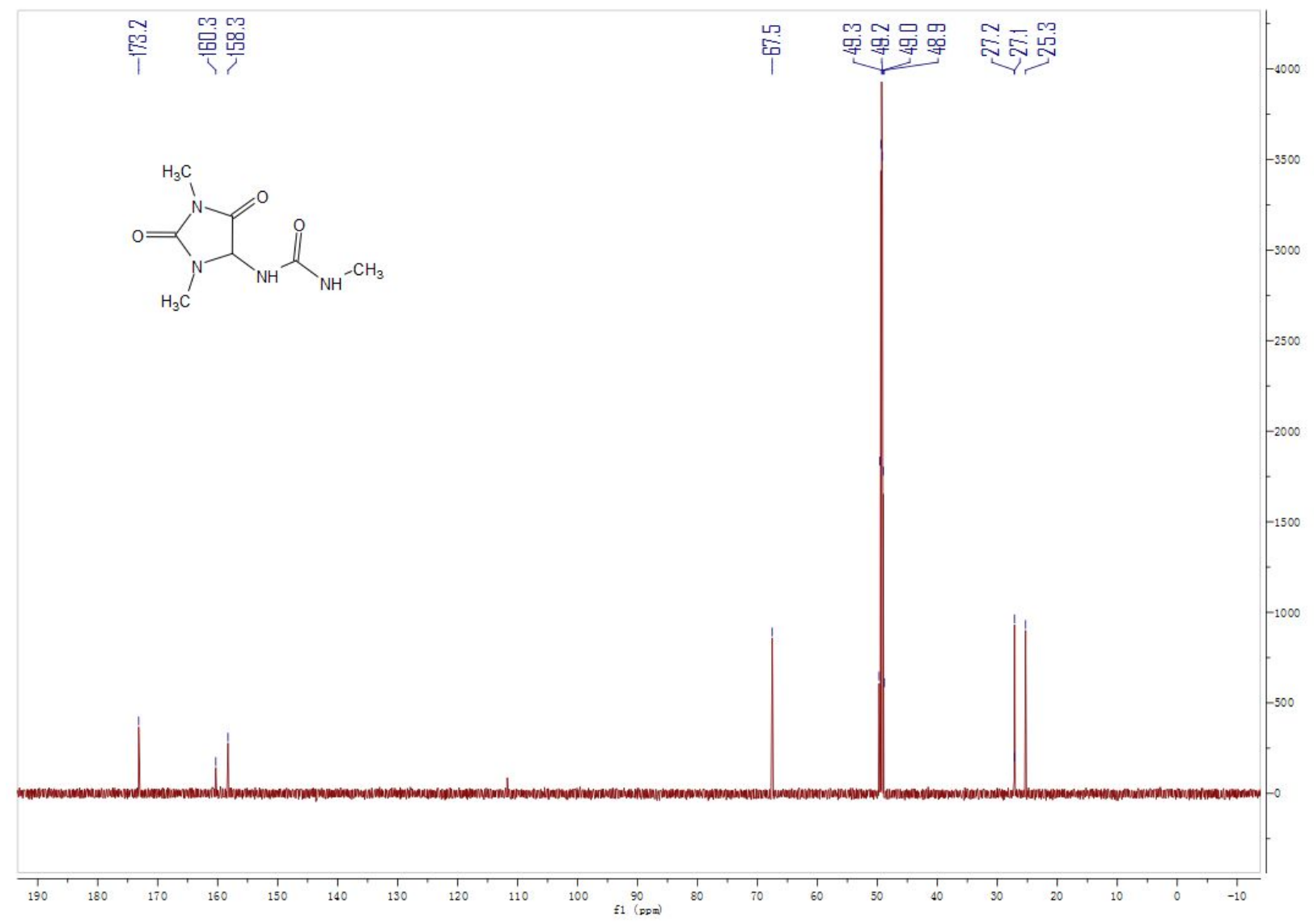

Figure S6. ${ }^{13} \mathrm{C}$ NMR spectrum of $\mathbf{1}$ in $\mathrm{CD}_{3} \mathrm{OD}$

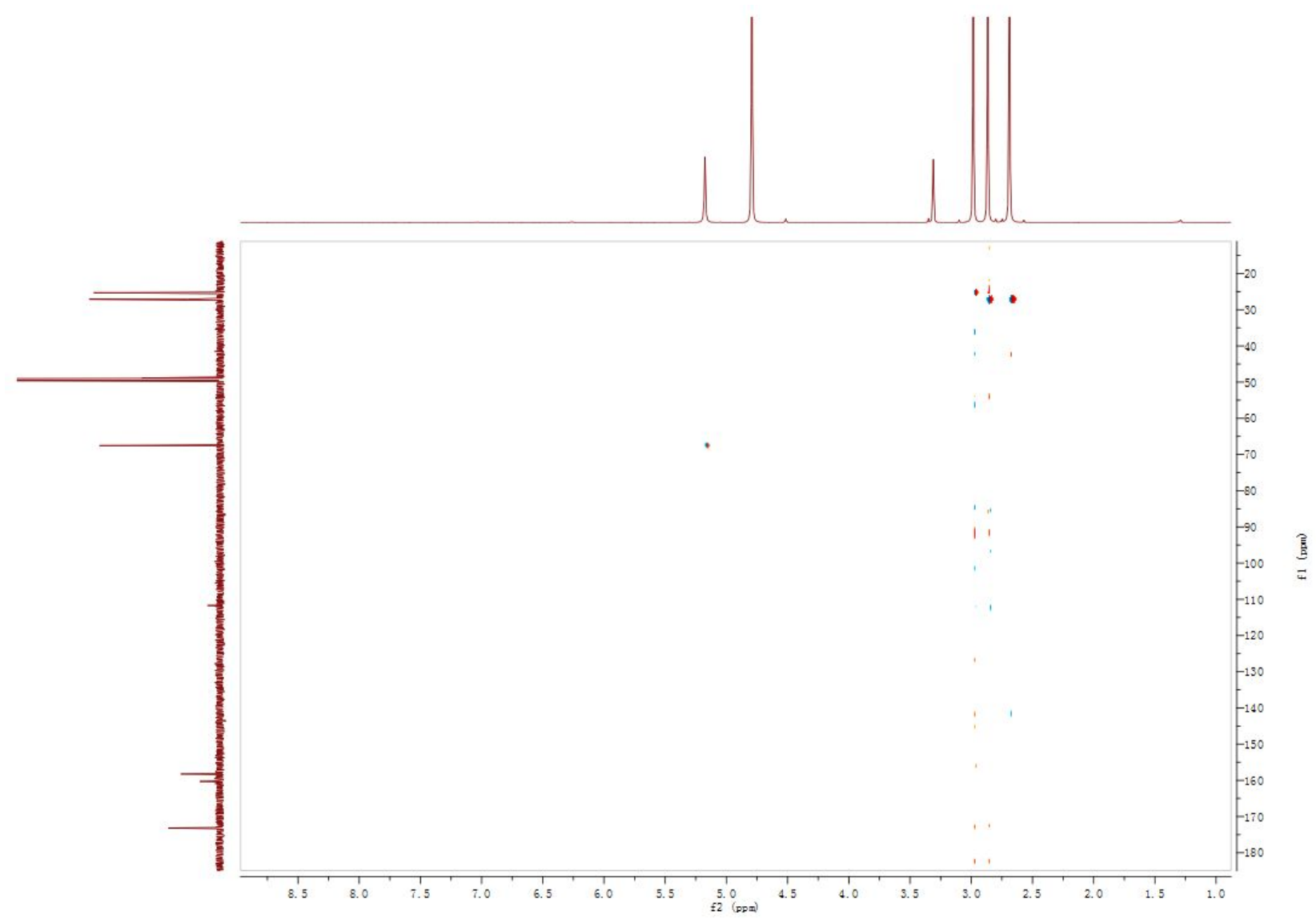

Figure S7. HMQC spectrum of $\mathbf{1}$

12 


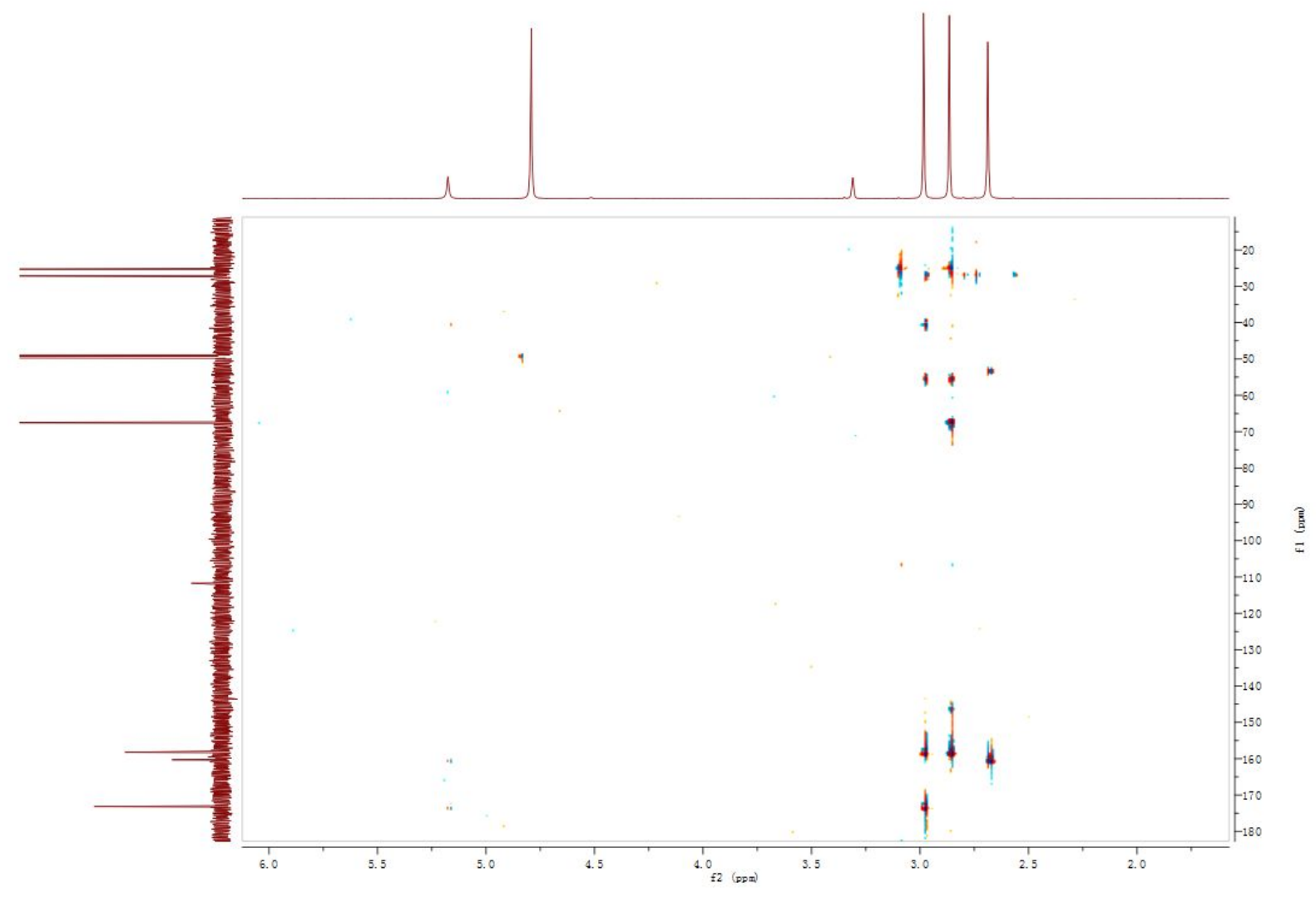

Figure S8. HMBC spectrum of 1

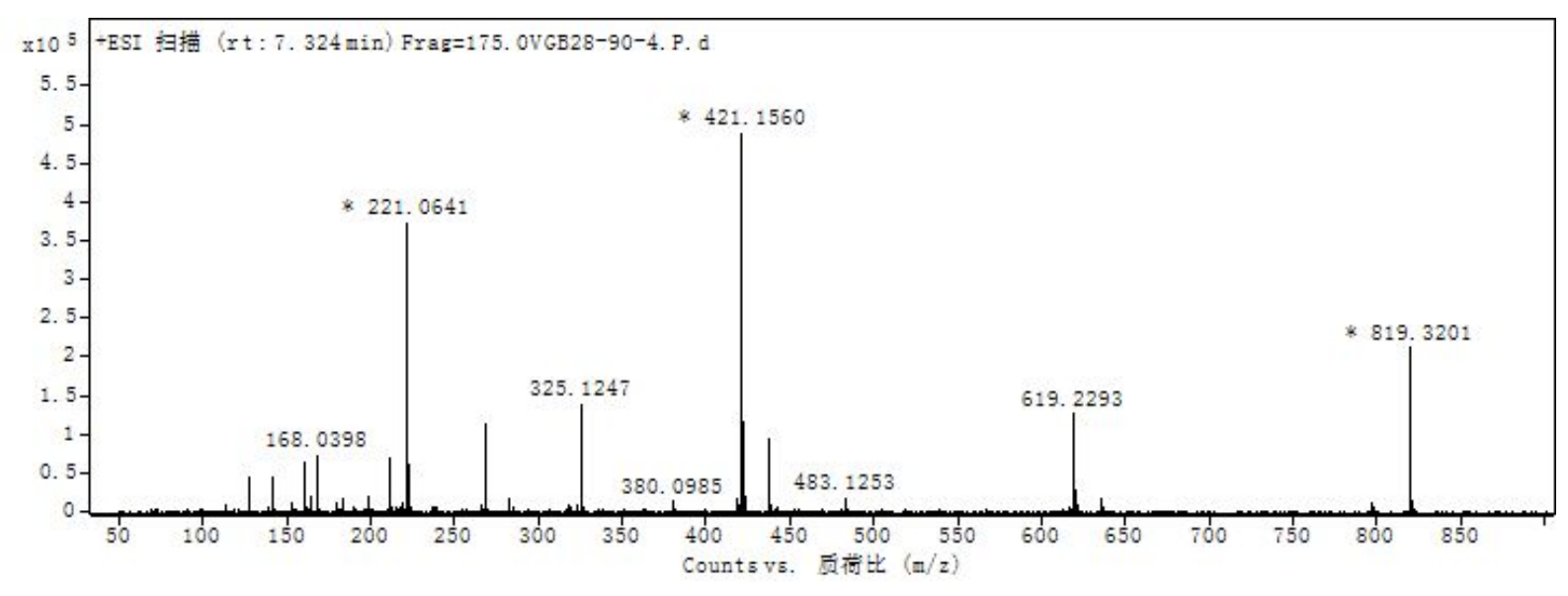

Figure S9. HR-ESI-MS spectrum of 2

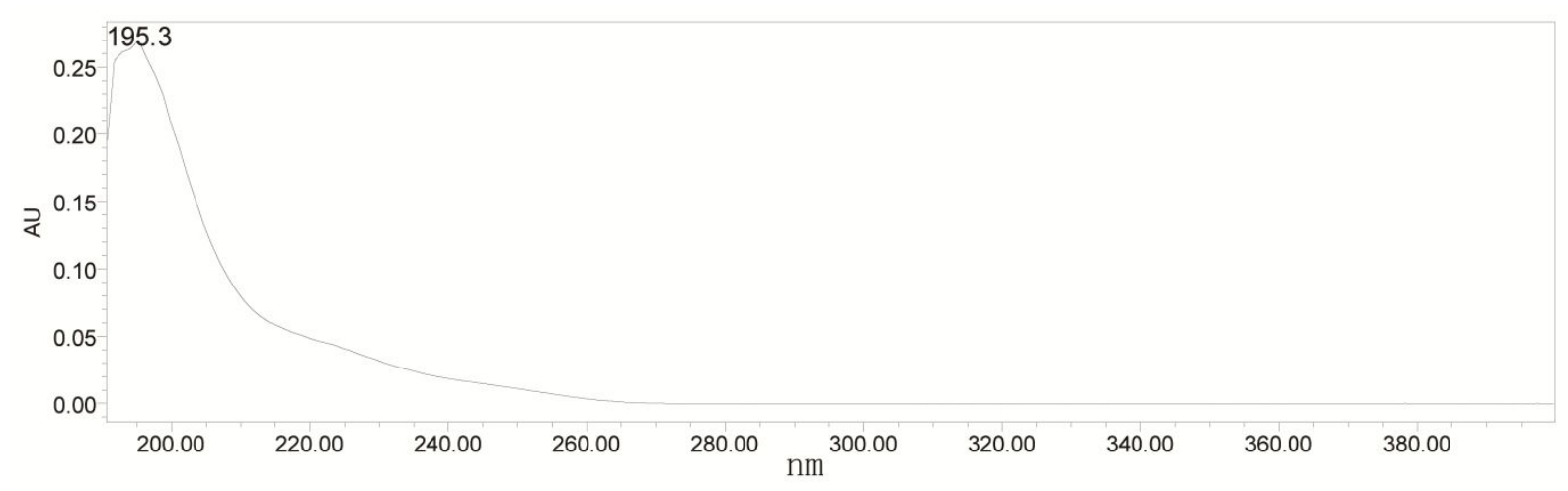

Figure S10. UV spectrum of 2 


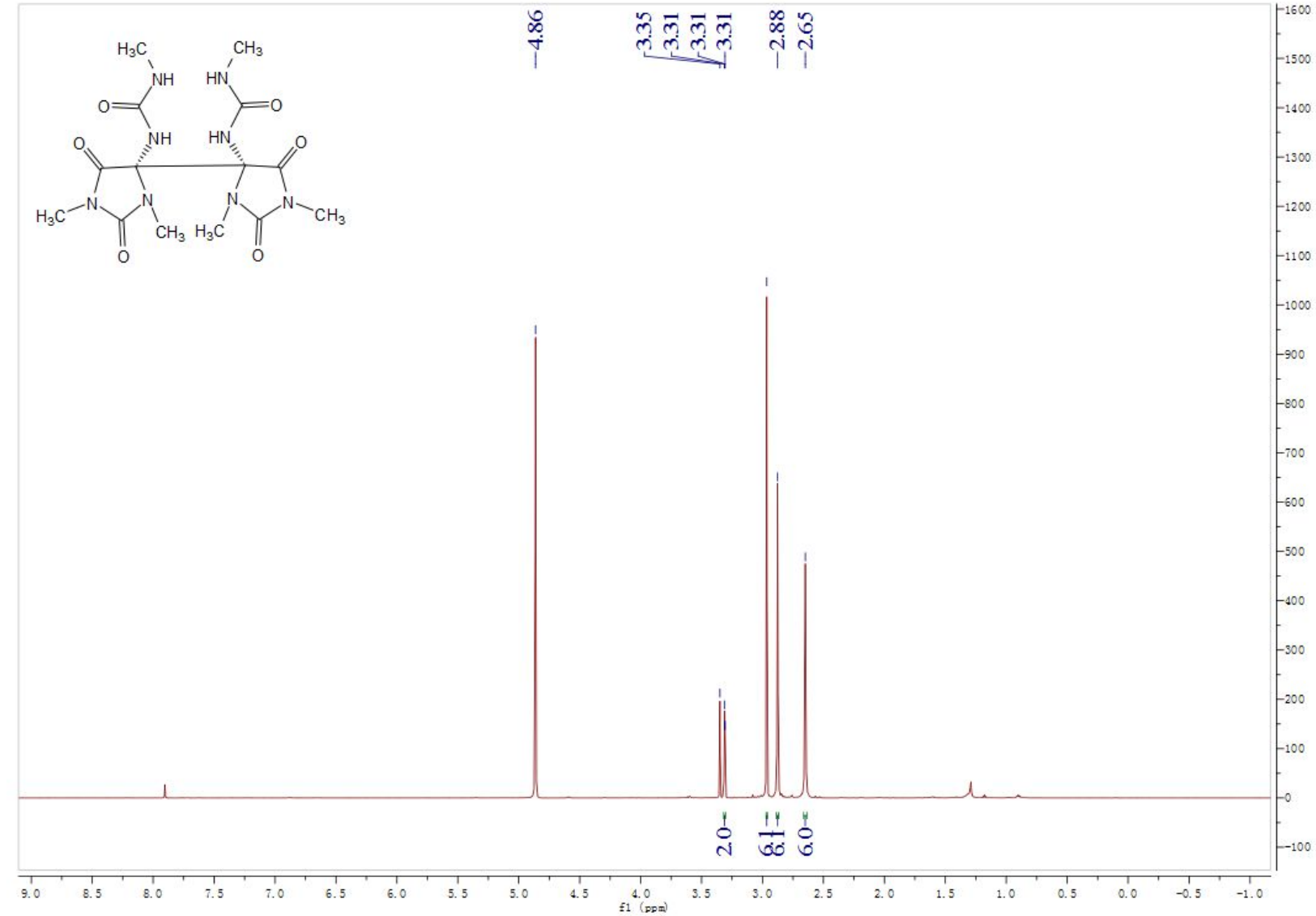

Figure S11. ${ }^{1} \mathrm{H}$ NMR spectrum of 2 in $\mathrm{CD}_{3} \mathrm{OD}$

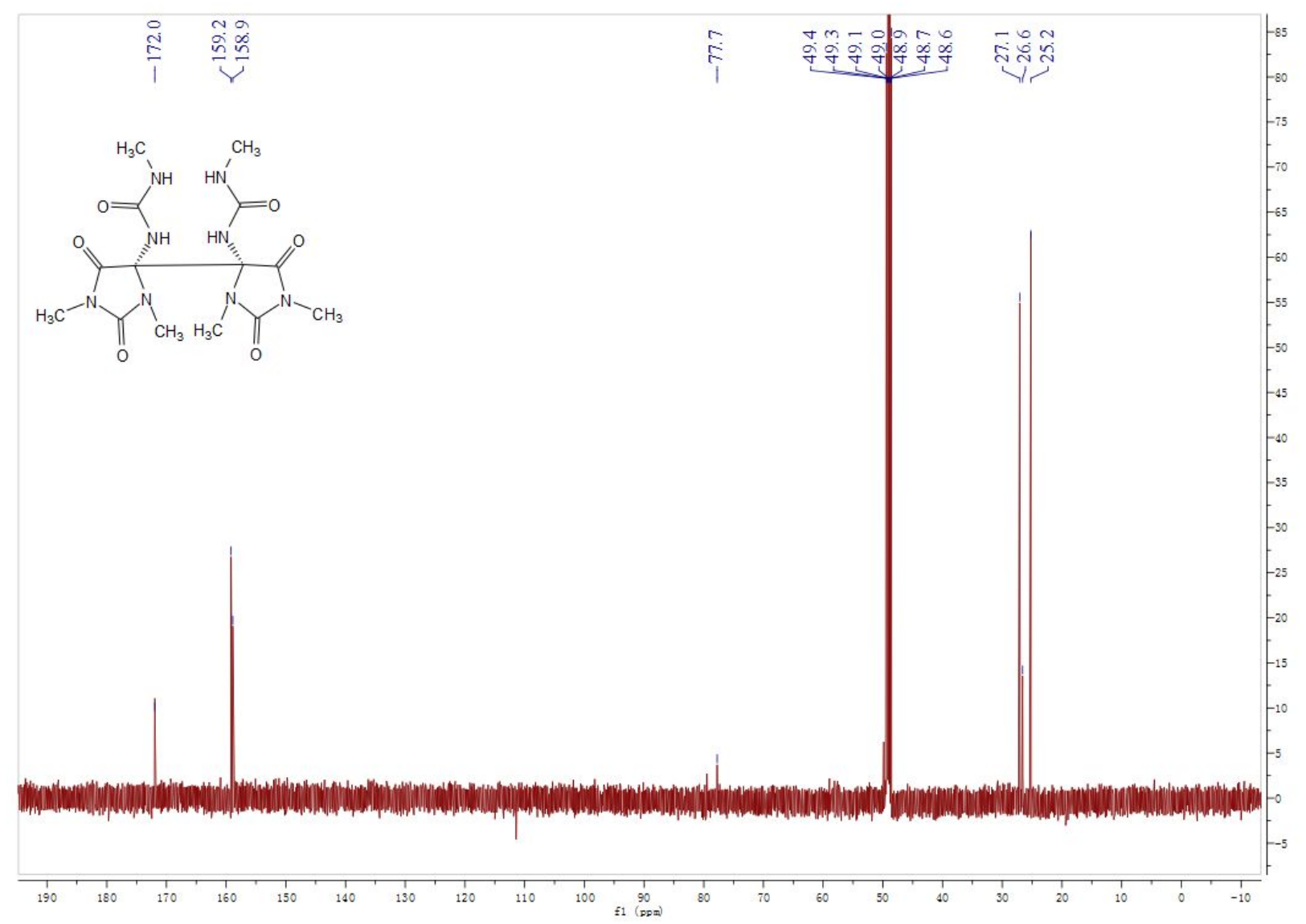

Figure S12. ${ }^{13} \mathrm{C}$ NMR spectrum of 2 in $\mathrm{CD}_{3} \mathrm{OD}$ 


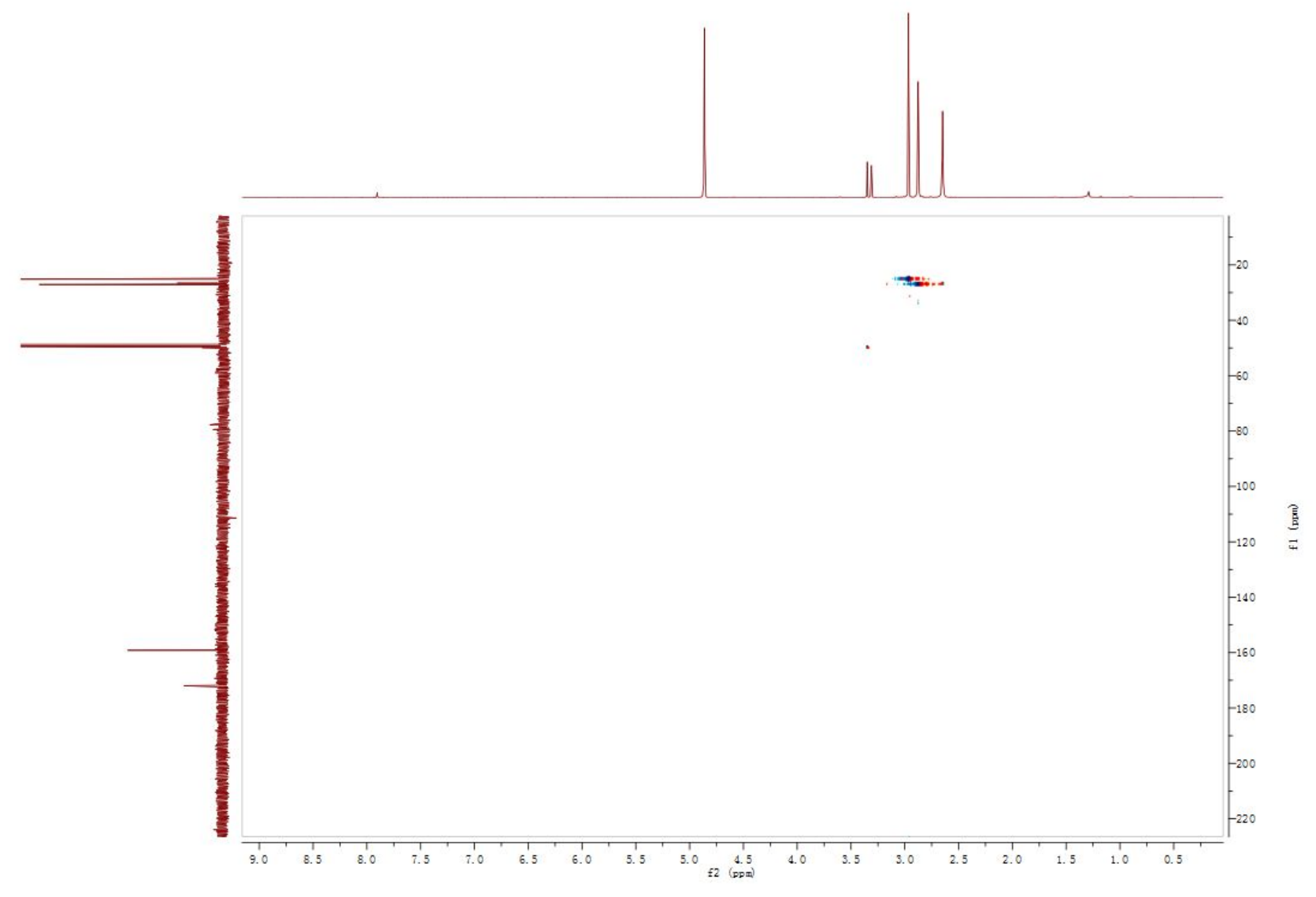

Figure S13. HSQC spectrum of 2

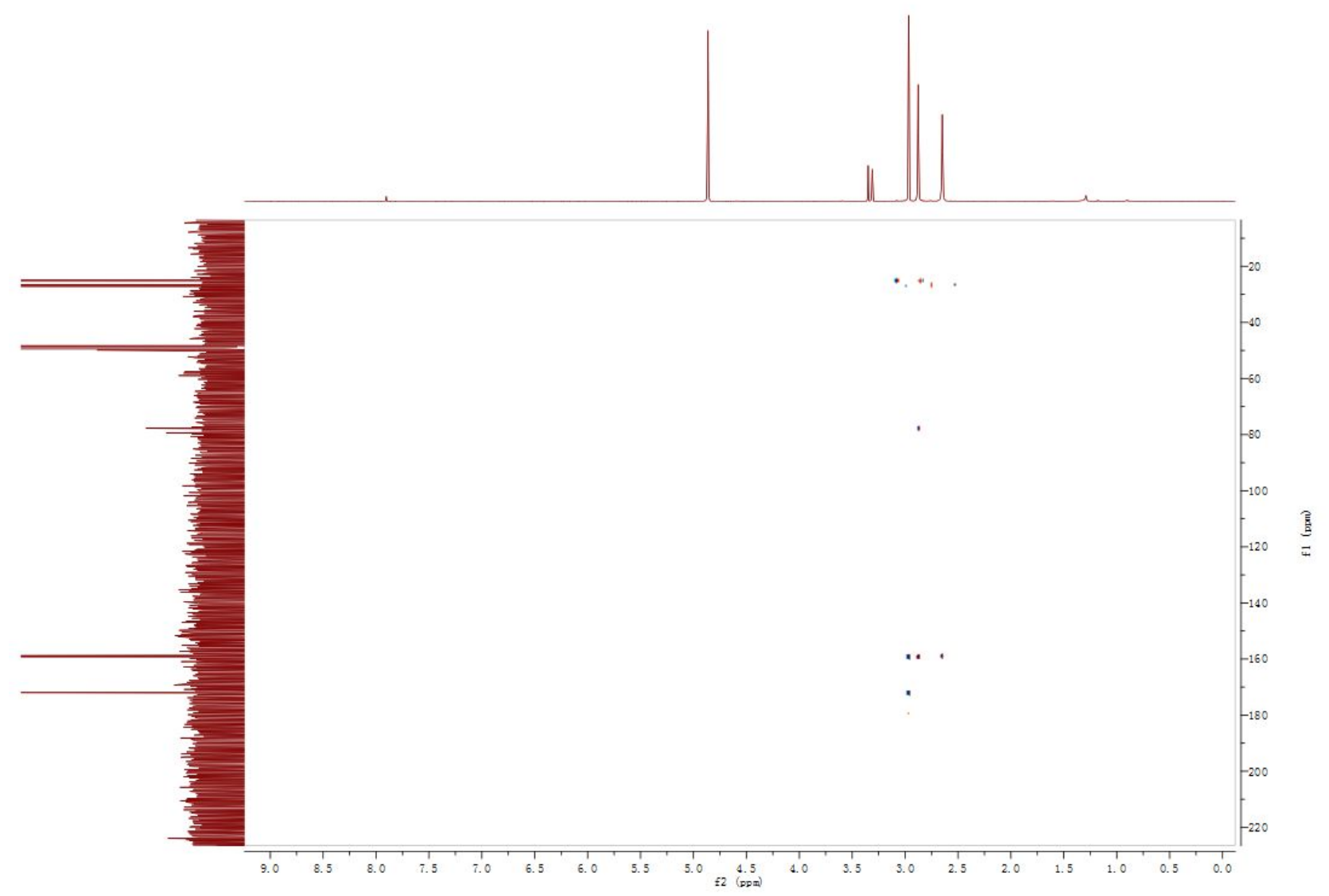

Figure S14. HMBC spectrum of 2 


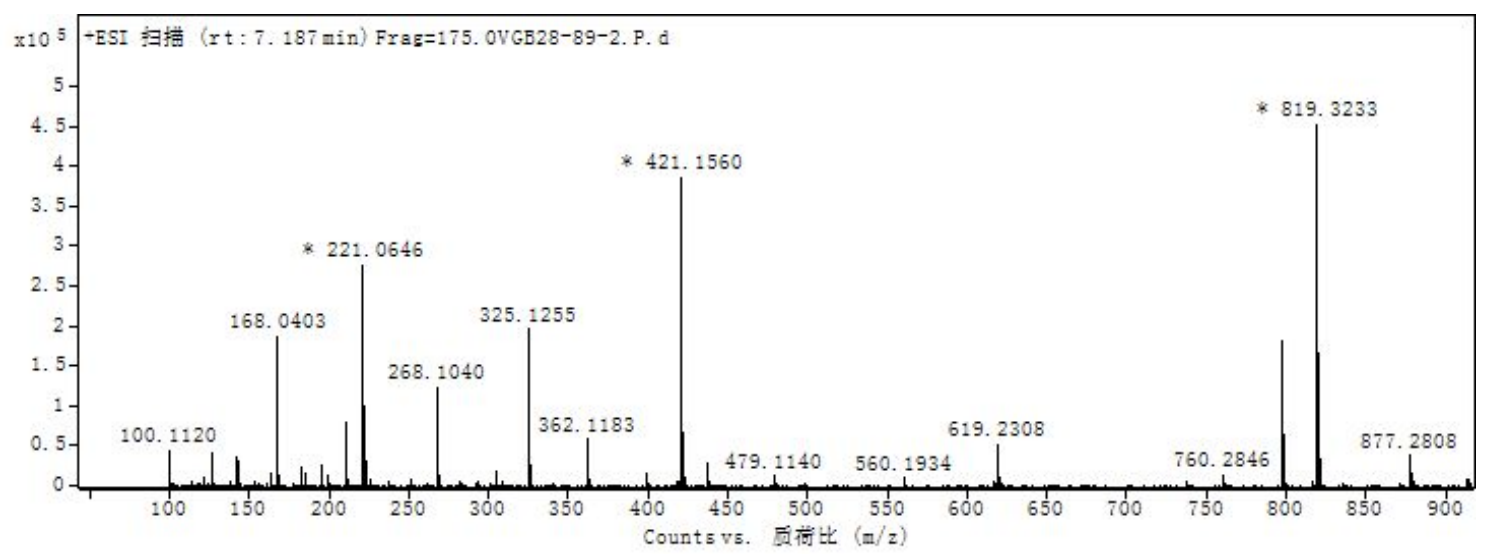

Figure S15. HR-ESI-MS spectrum of $\mathbf{3}$

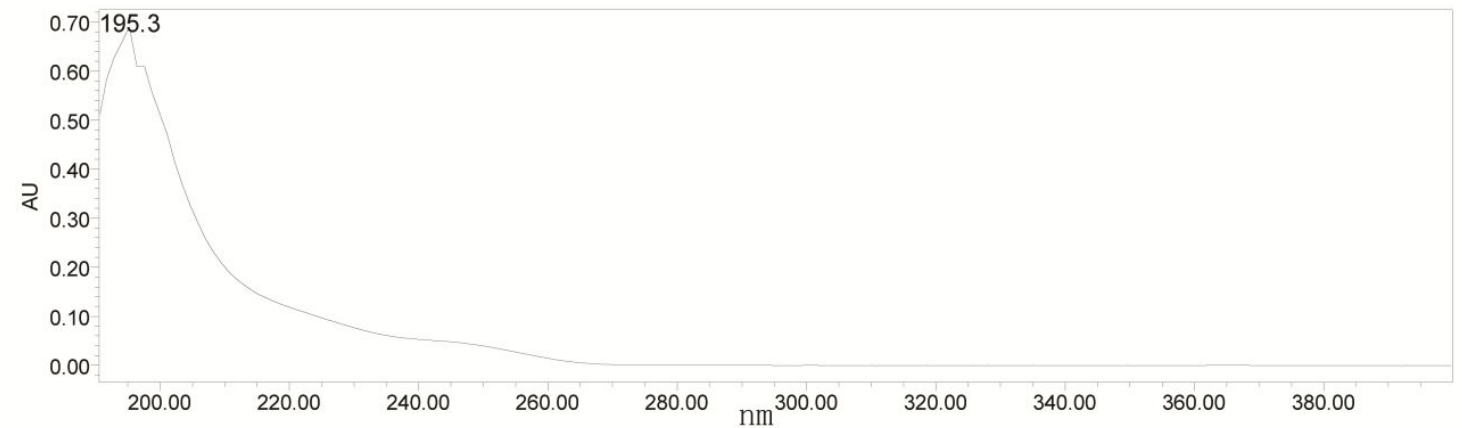

Figure S16. UV spectrum of 3

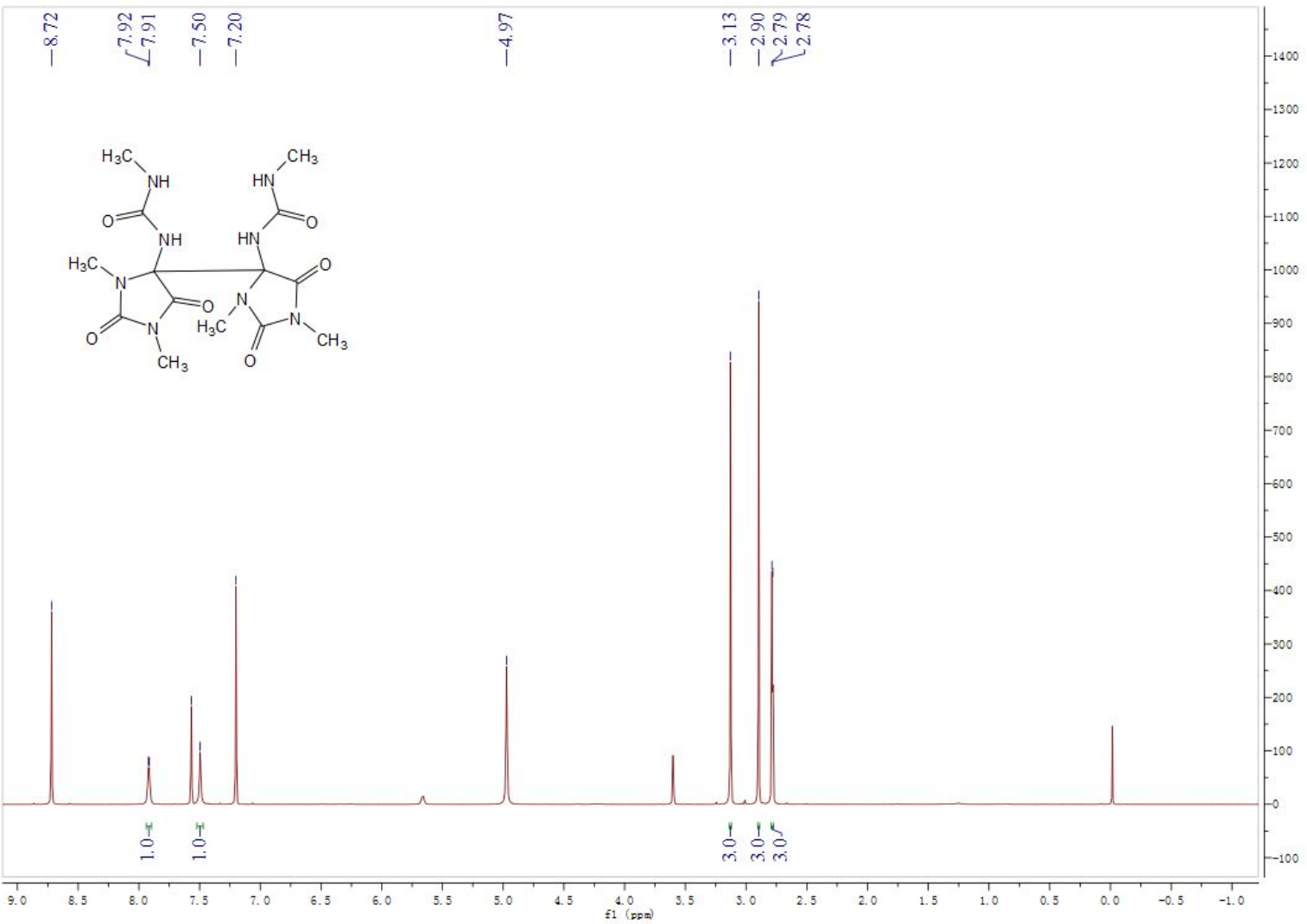

Figure S17. ${ }^{1} \mathrm{H}$ NMR spectrum of 3 in $\mathrm{C}_{5} \mathrm{D}_{5} \mathrm{~N}$ 


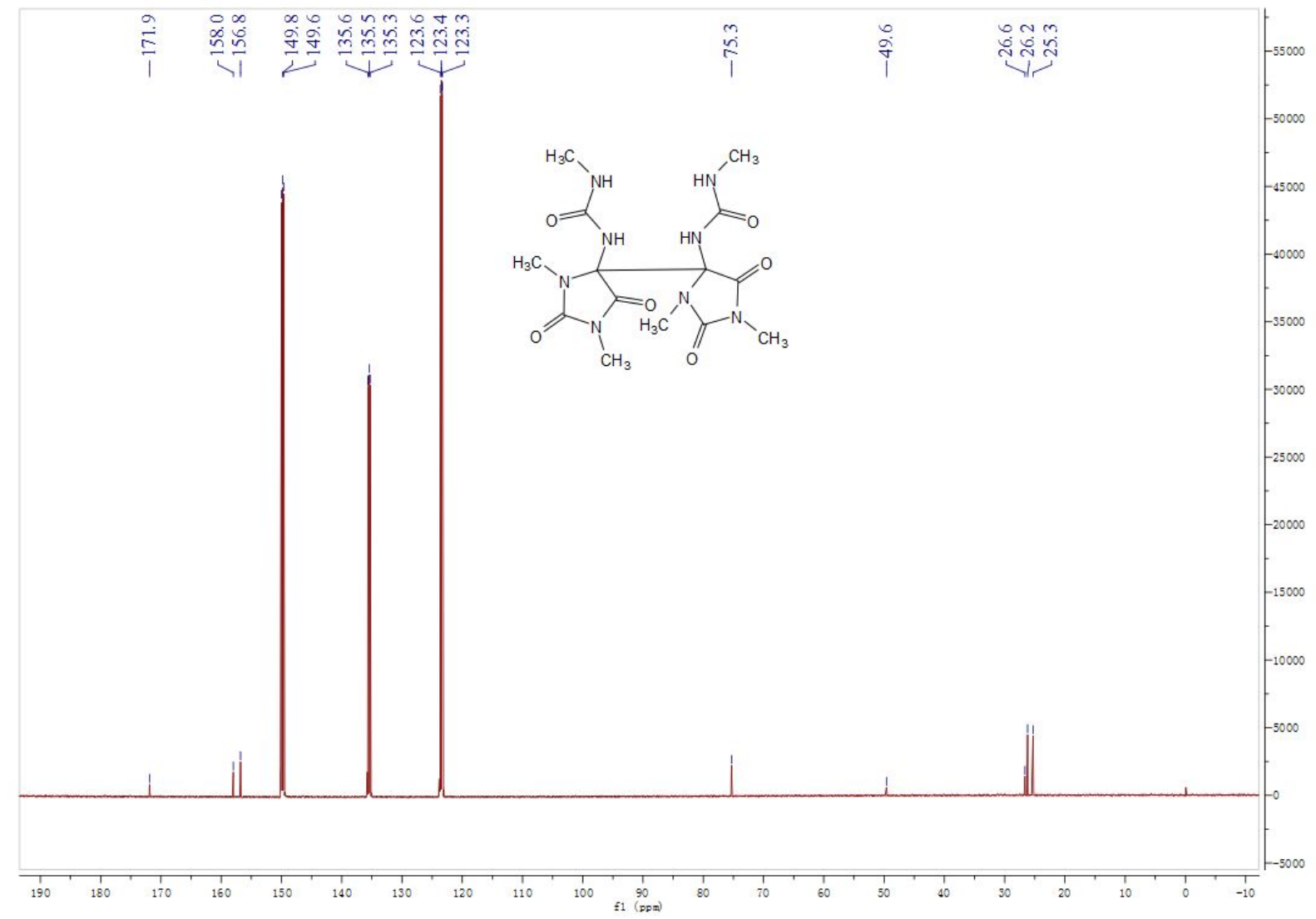

Figure S18. ${ }^{13} \mathrm{C}$ NMR spectrum of 3 in $\mathrm{C}_{5} \mathrm{D}_{5} \mathrm{~N}$

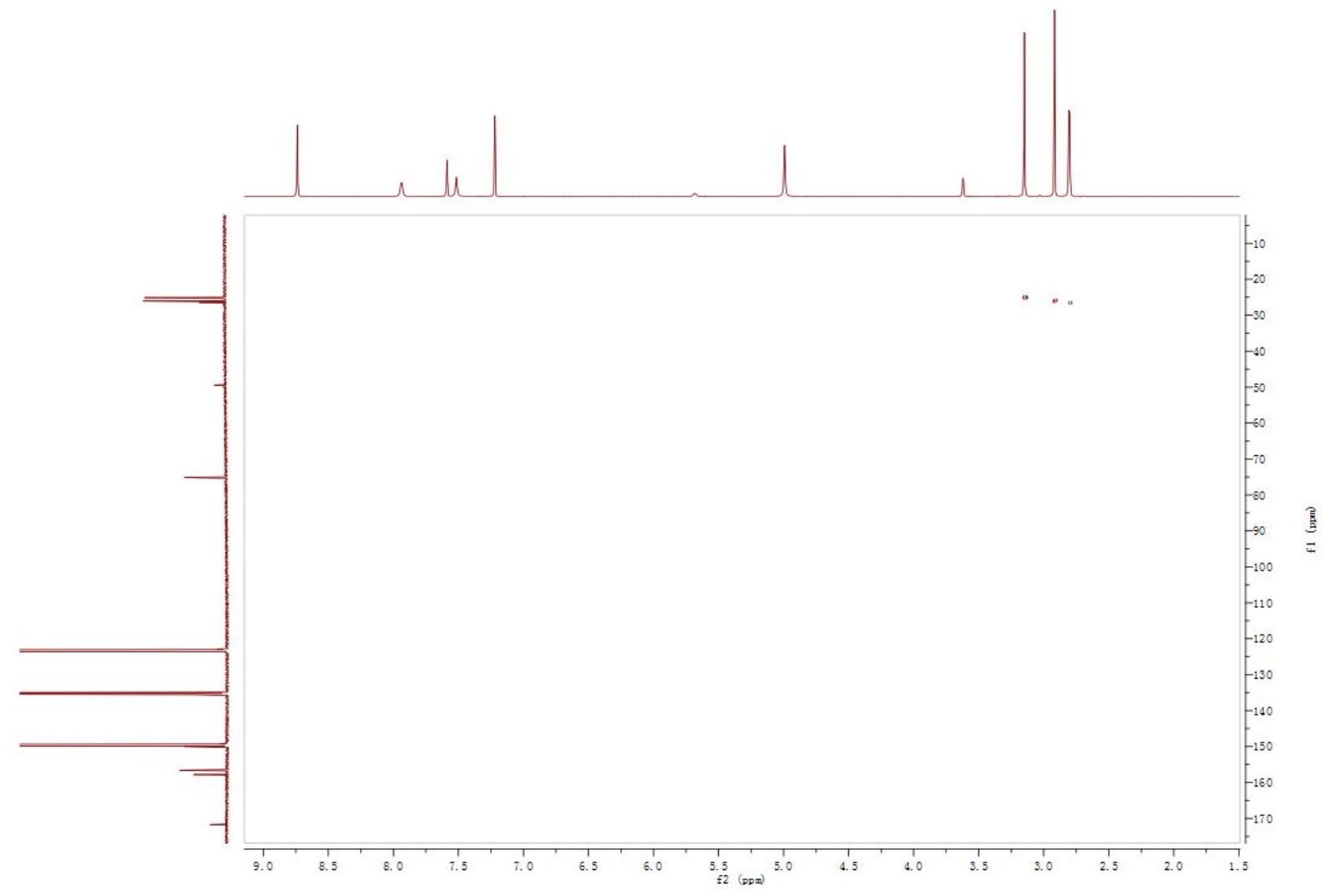

Figure S19. HSQC spectrum of $\mathbf{3}$ 


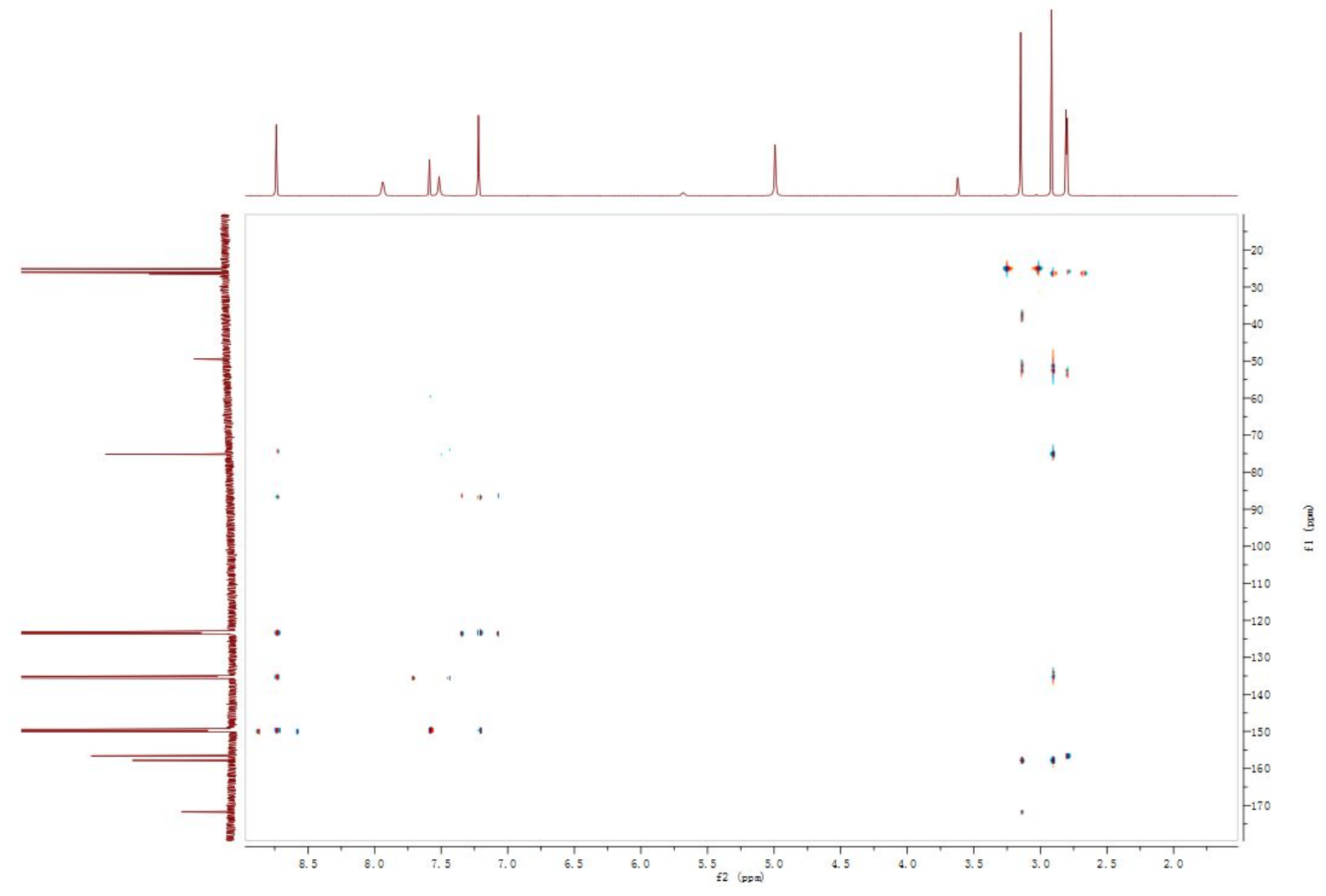

Figure S20. HMBC spectrum of $\mathbf{3}$

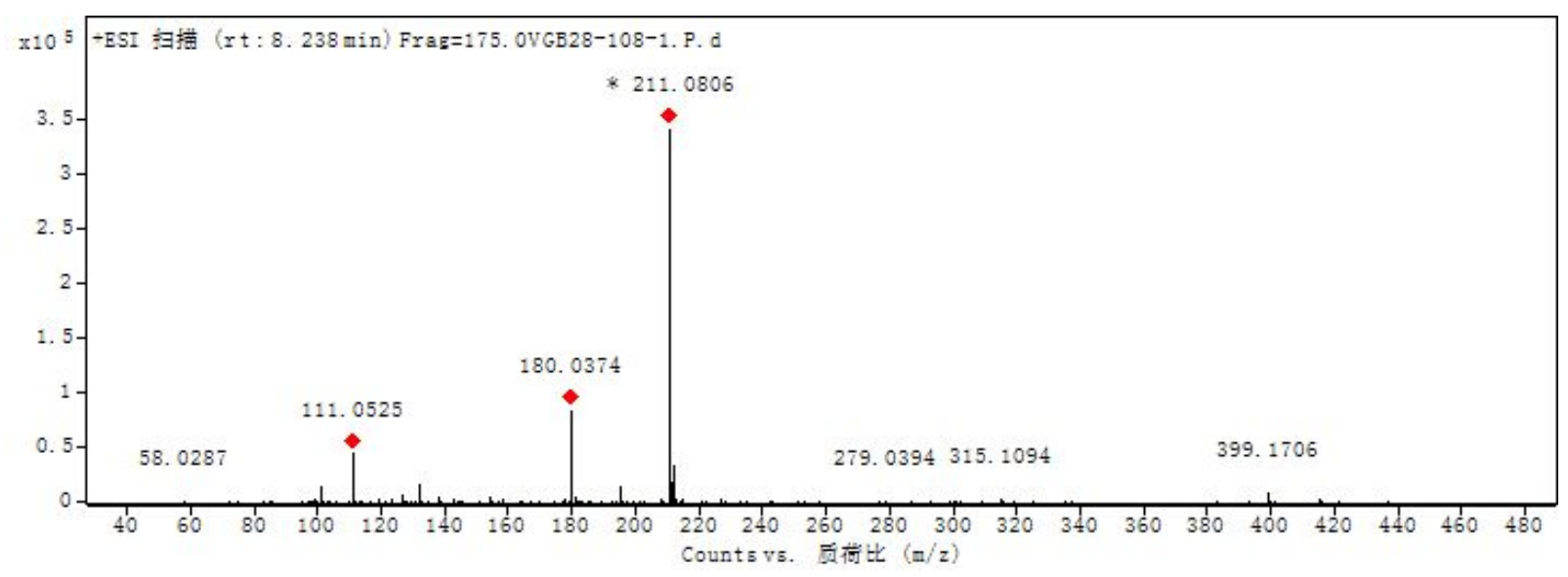

Figure S21. HR-ESI-MS spectrum of 4

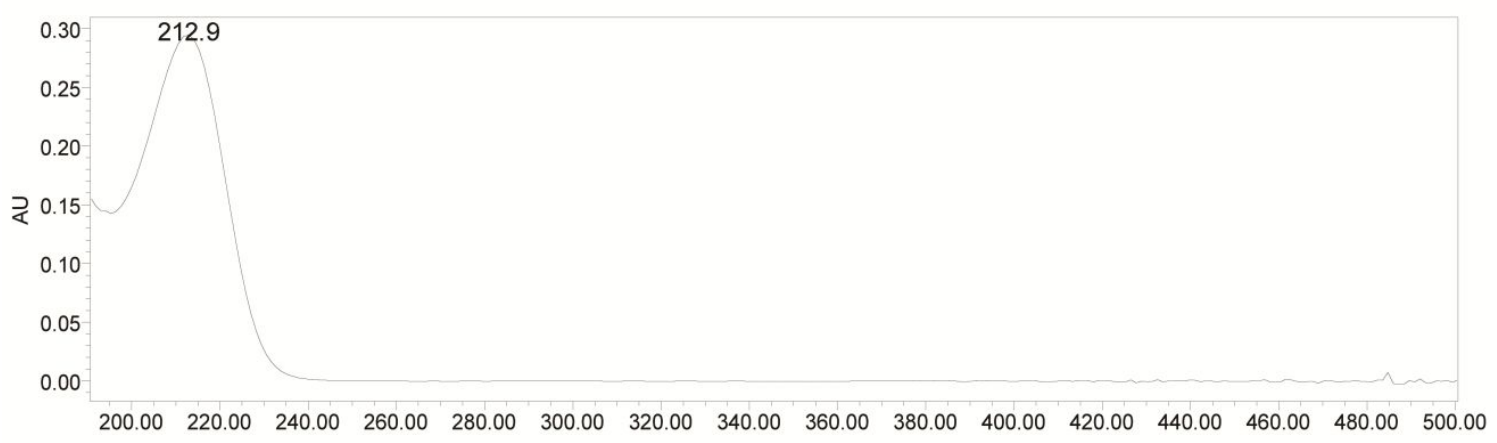

Figure S22. UV spectrum of 4 


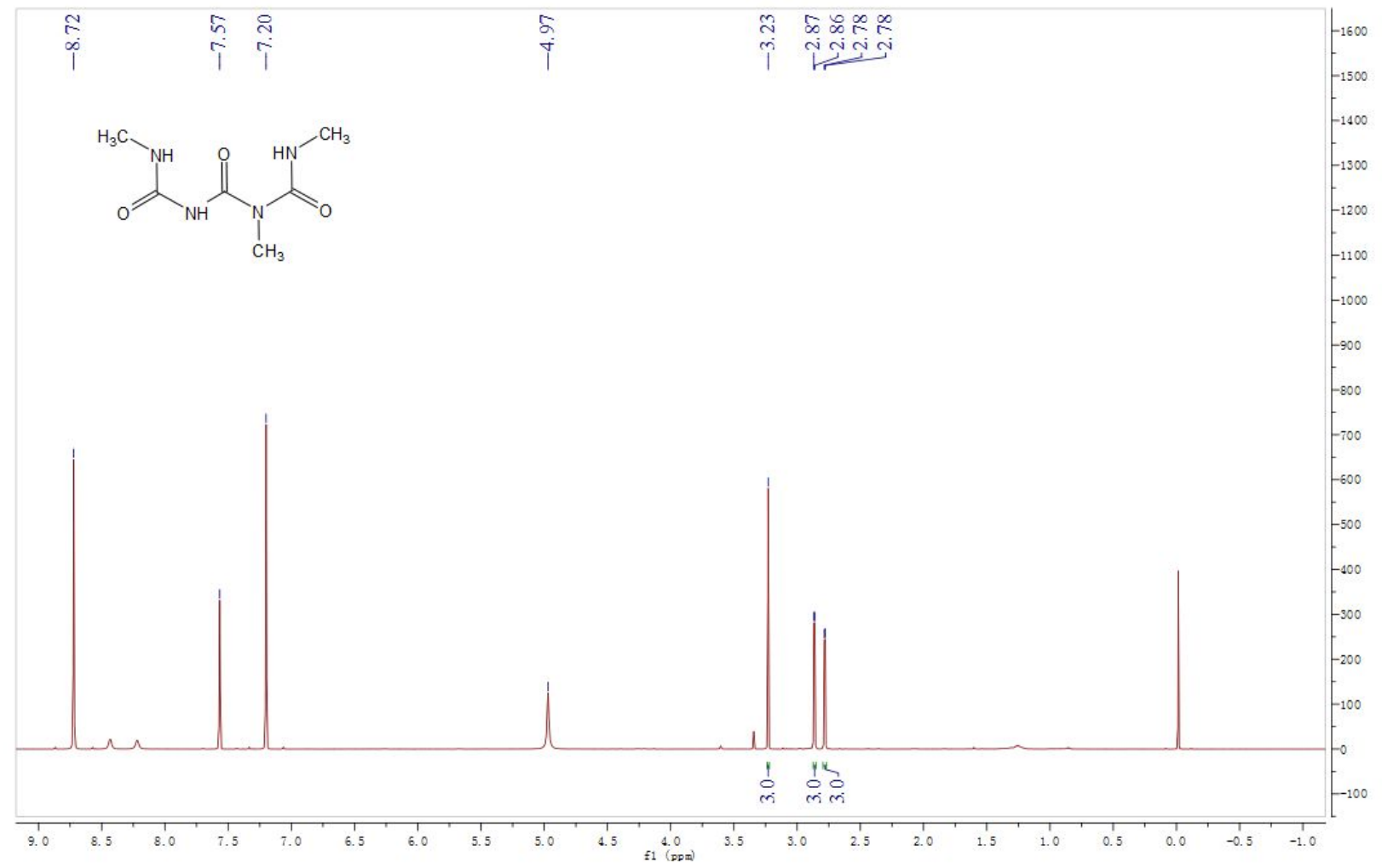

Figure S23. ${ }^{1} \mathrm{H}$ NMR spectrum of 4 in $\mathrm{C}_{5} \mathrm{D}_{5} \mathrm{~N}$

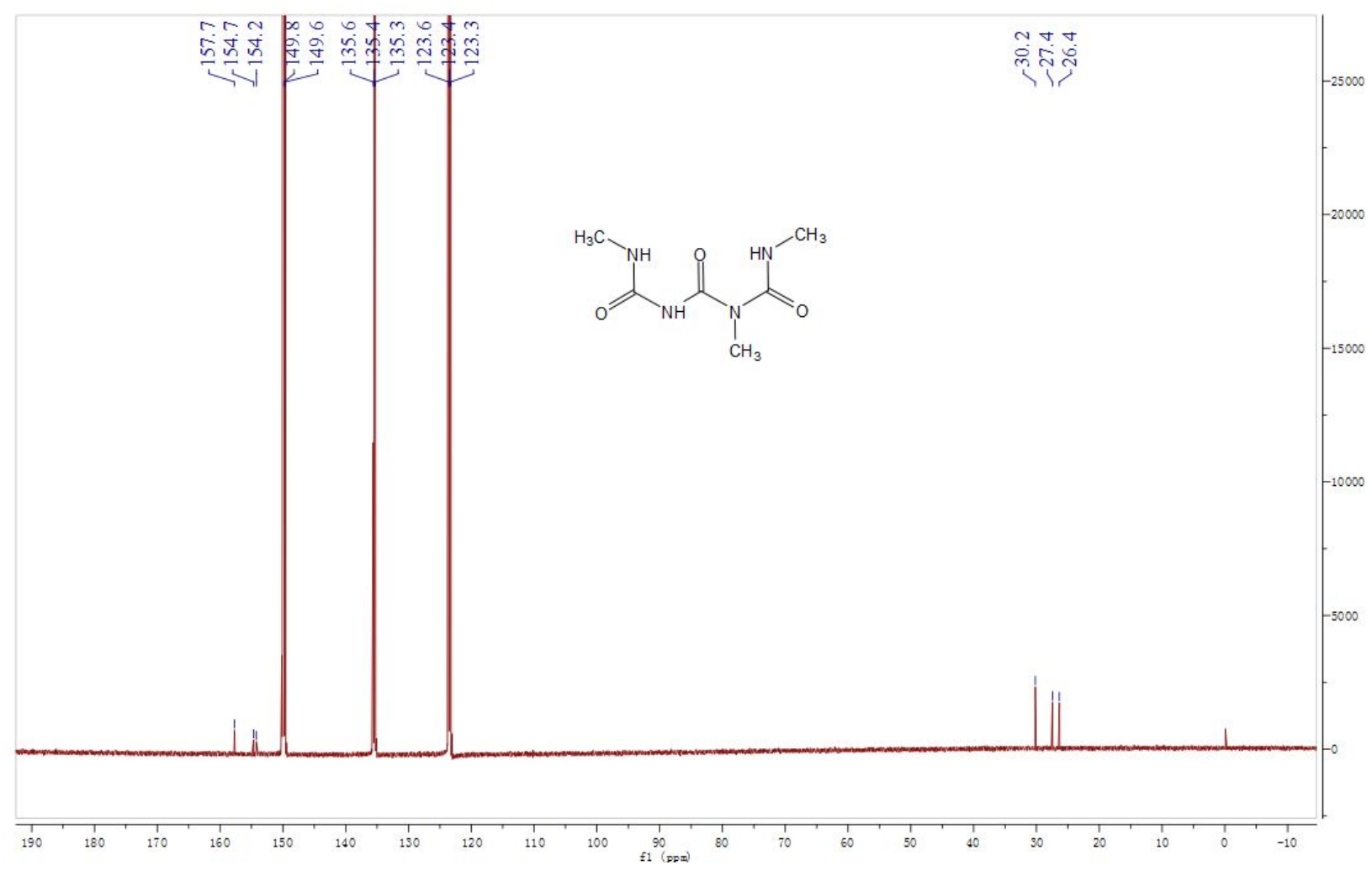

Figure S24. ${ }^{13} \mathrm{C}$ NMR spectrum of 4 in $\mathrm{C}_{5} \mathrm{D}_{5} \mathrm{~N}$ 


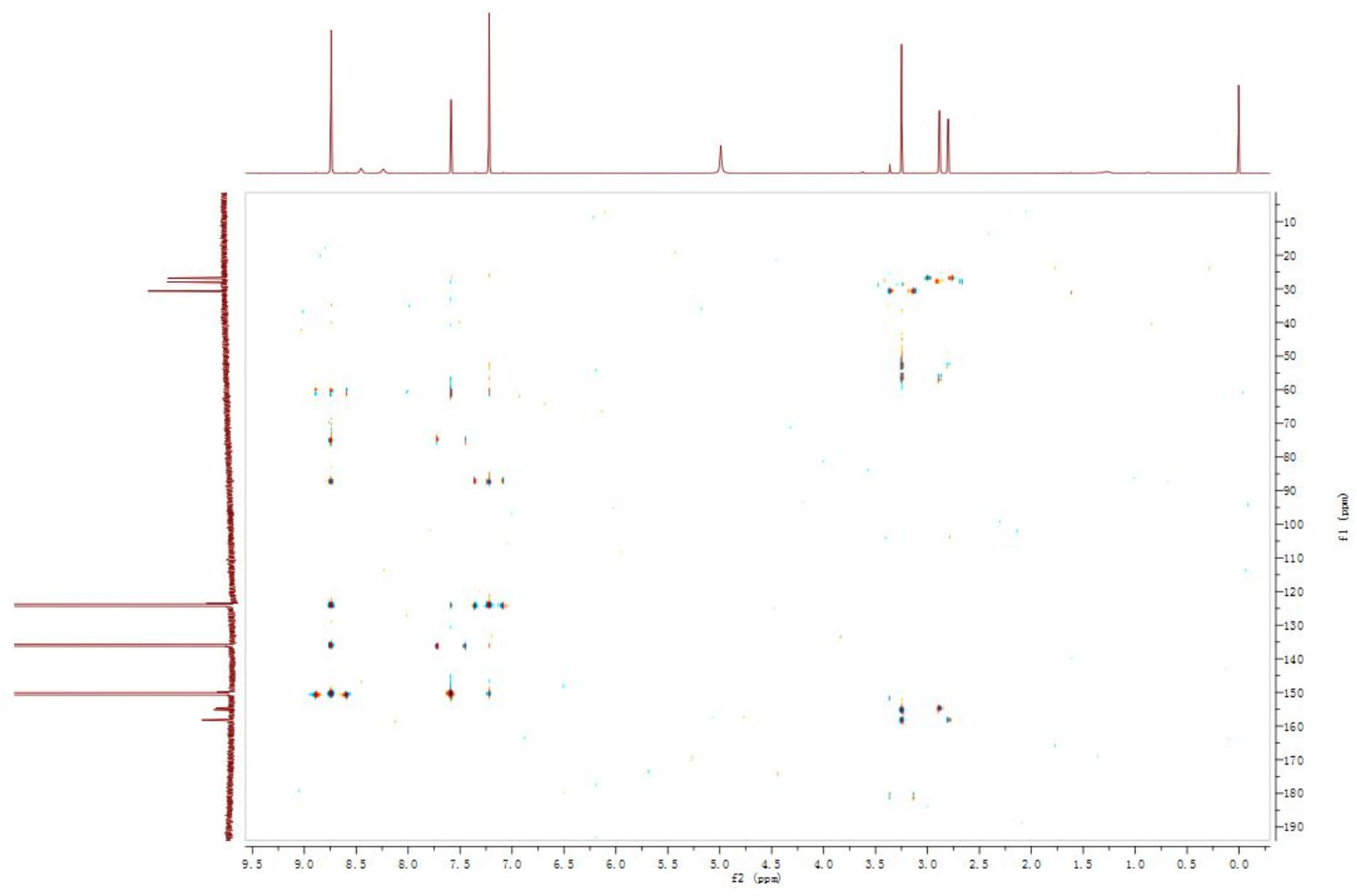

Figure S25. HMBC spectrum of 4

6. Chiral separation of compounds 1 and 3 by HPLC and HPLC analysis of compounds 1-4.

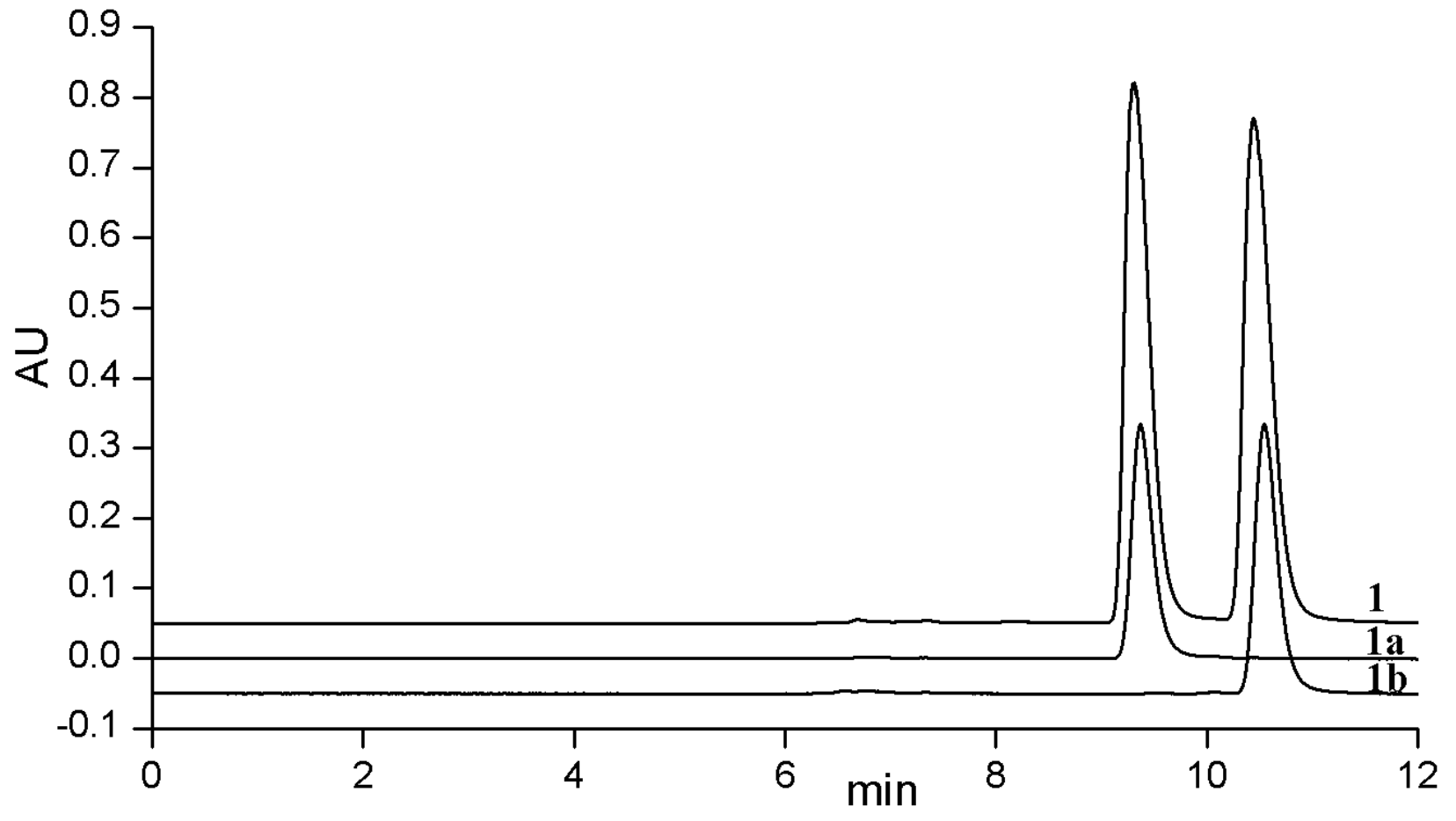

Figure S26. Chiral separation of $1(220 \mathrm{~nm})$ 


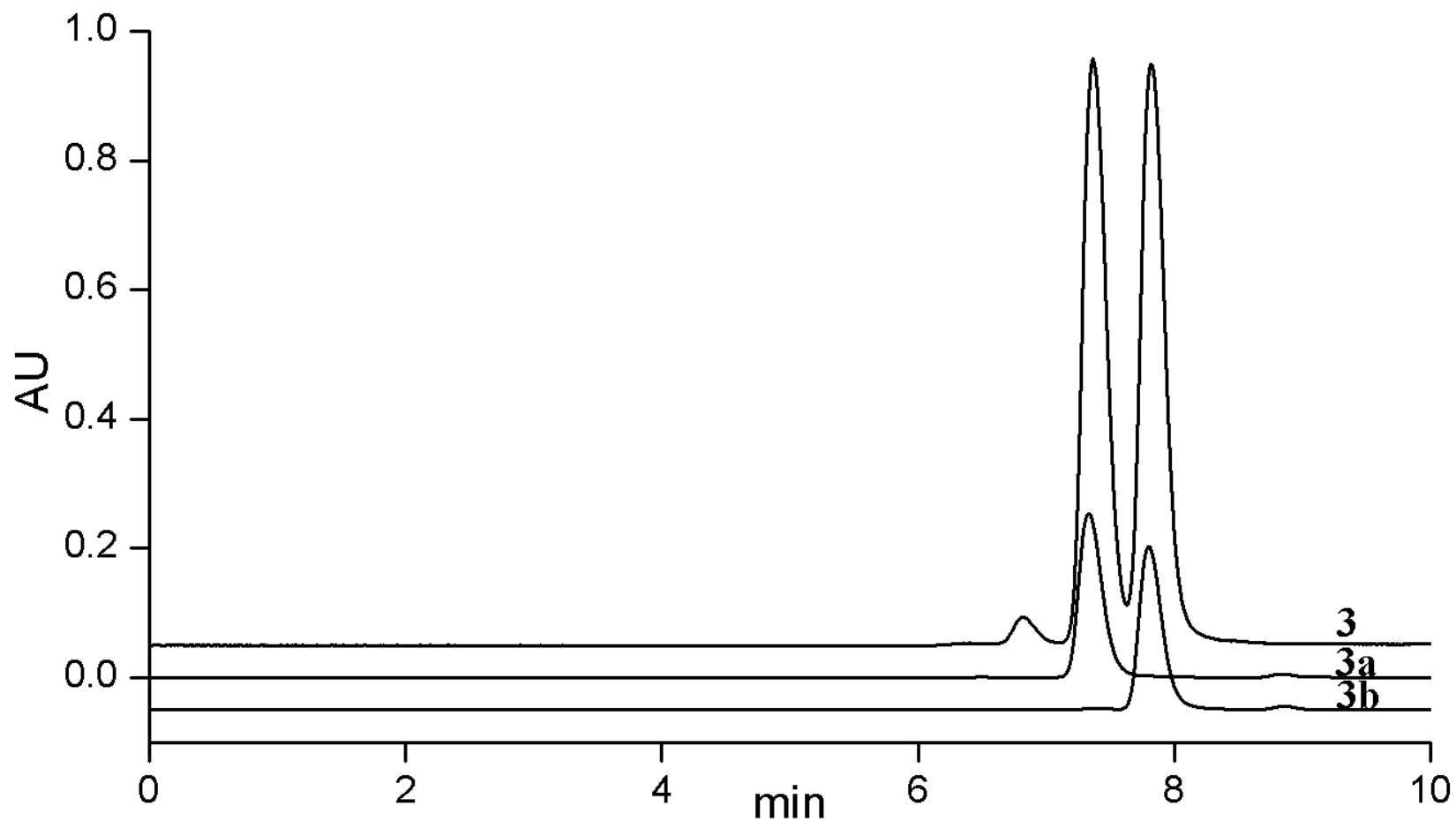

Figure S27. Chiral separation of $\mathbf{3}(220 \mathrm{~nm})$

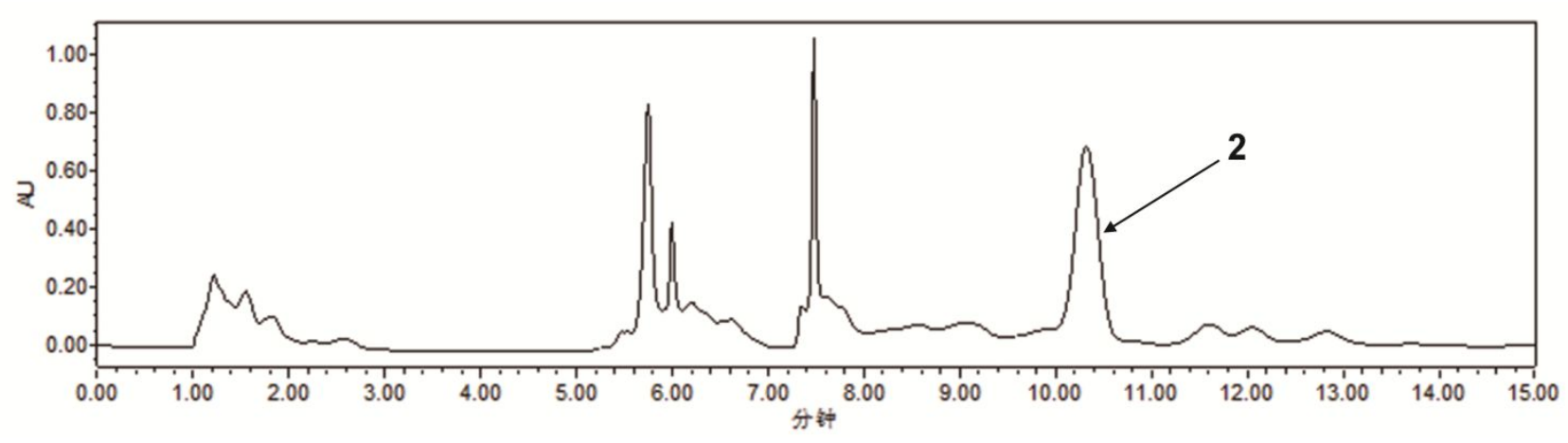

Figure S28. HPLC separation of $2(210 \mathrm{~nm})$

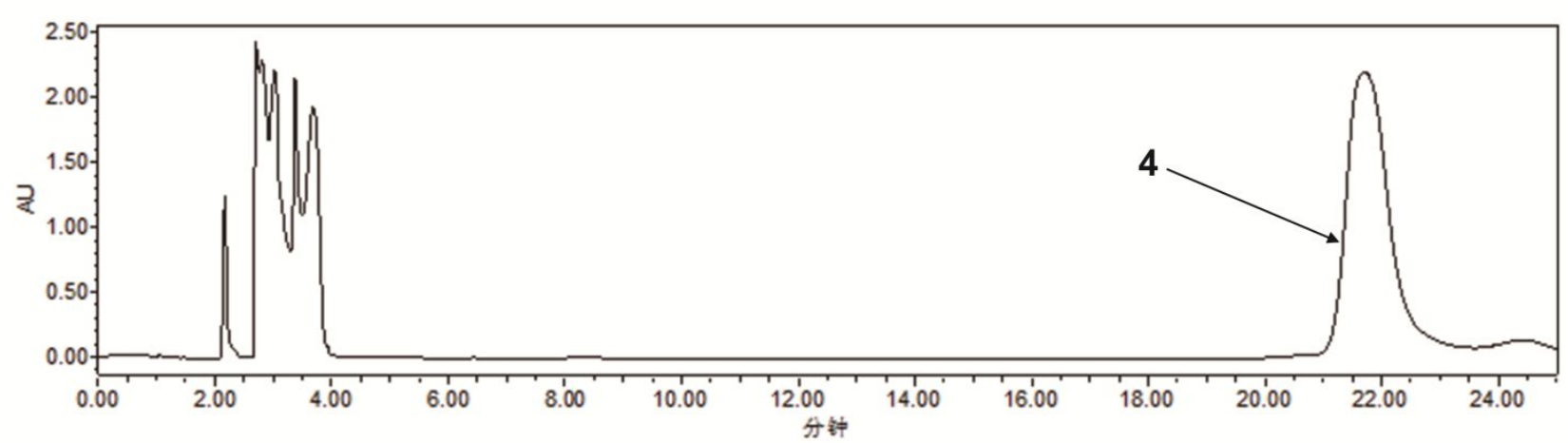

Figure S29. HPLC separation of $4(210 \mathrm{~nm})$ 


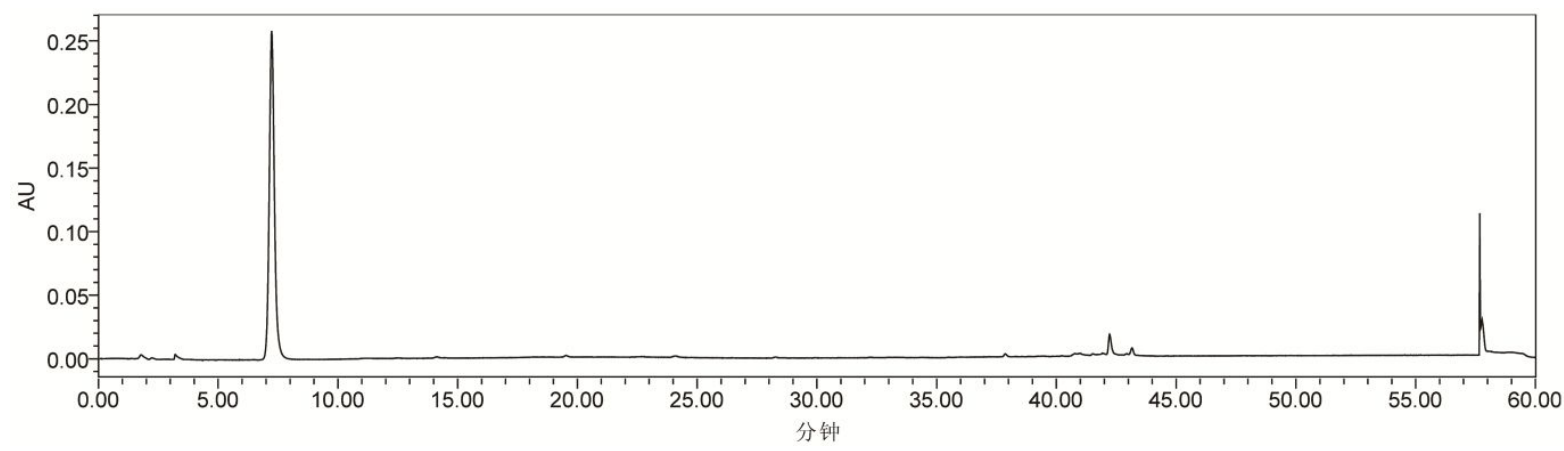

Figure S30. HPLC analysis of $\mathbf{1}(210 \mathrm{~nm})$

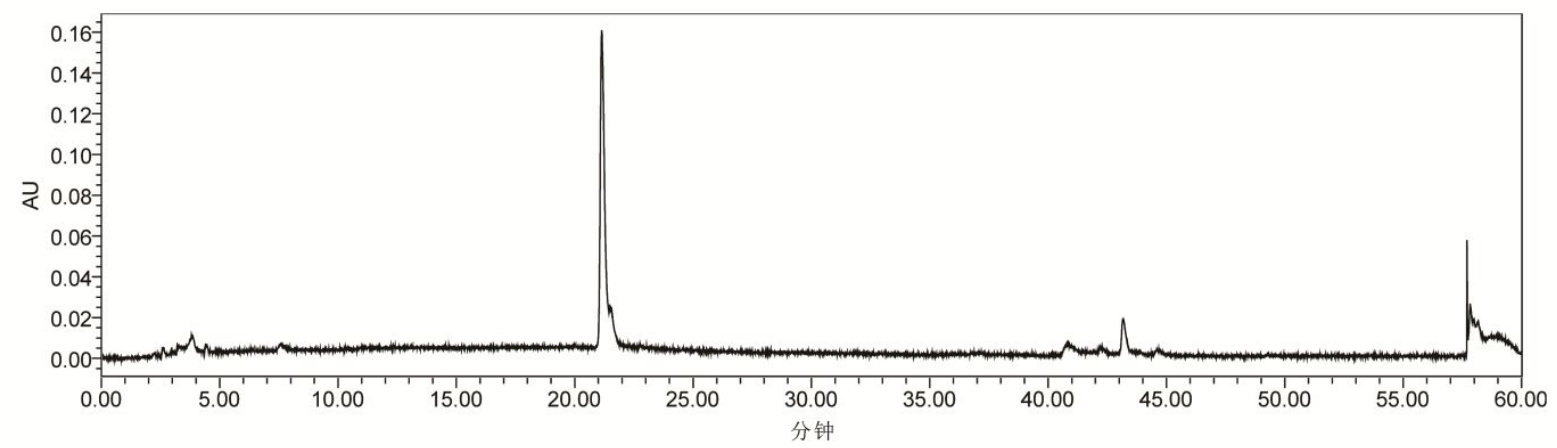

Figure S31. HPLC analysis of $2(205 \mathrm{~nm})$

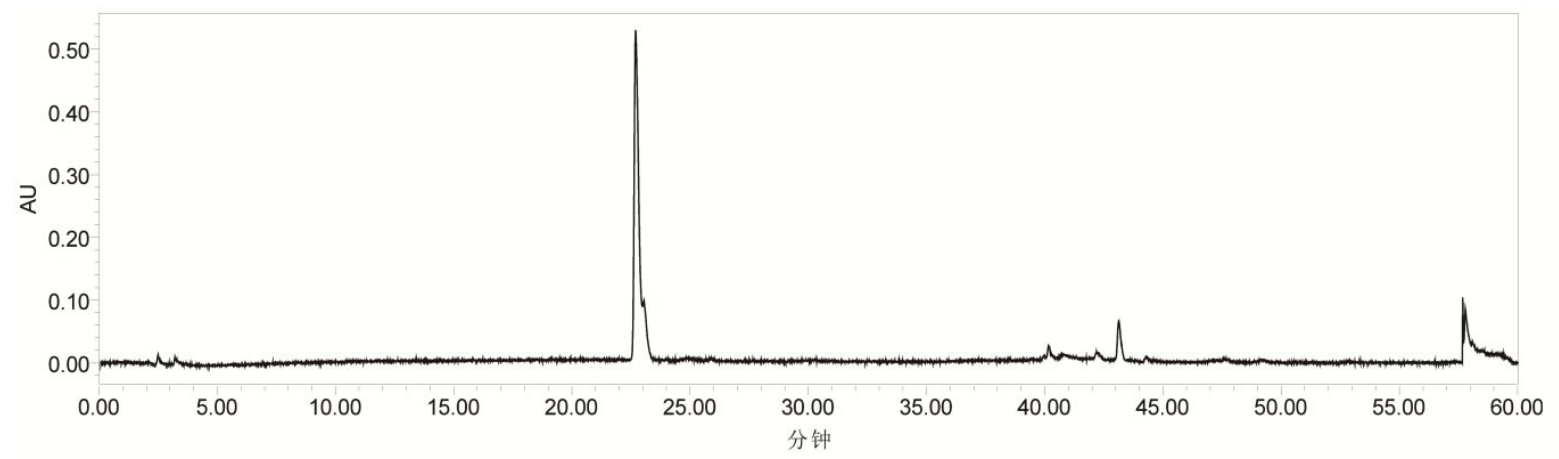

Figure S32. HPLC analysis of $\mathbf{3}(205 \mathrm{~nm})$

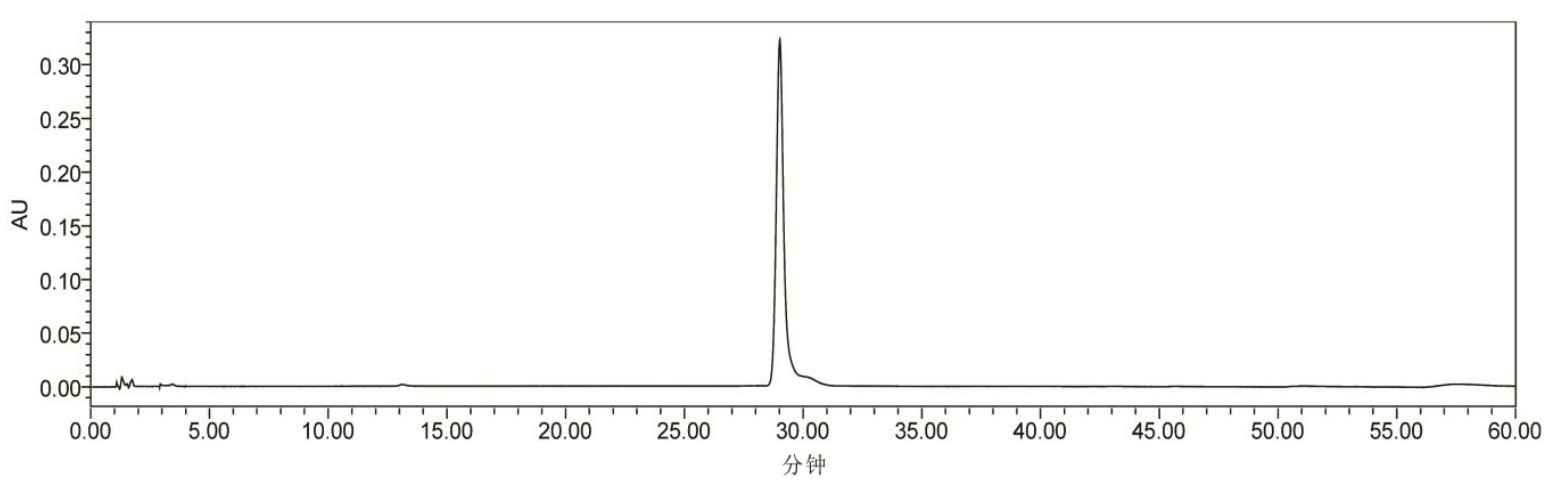

Figure S33. HPLC analysis of $4(210 \mathrm{~nm})$

7. UPLC-TOF-MS analyses of the extracts of the fresh leaves and the processed materials of Keemun black tea. 


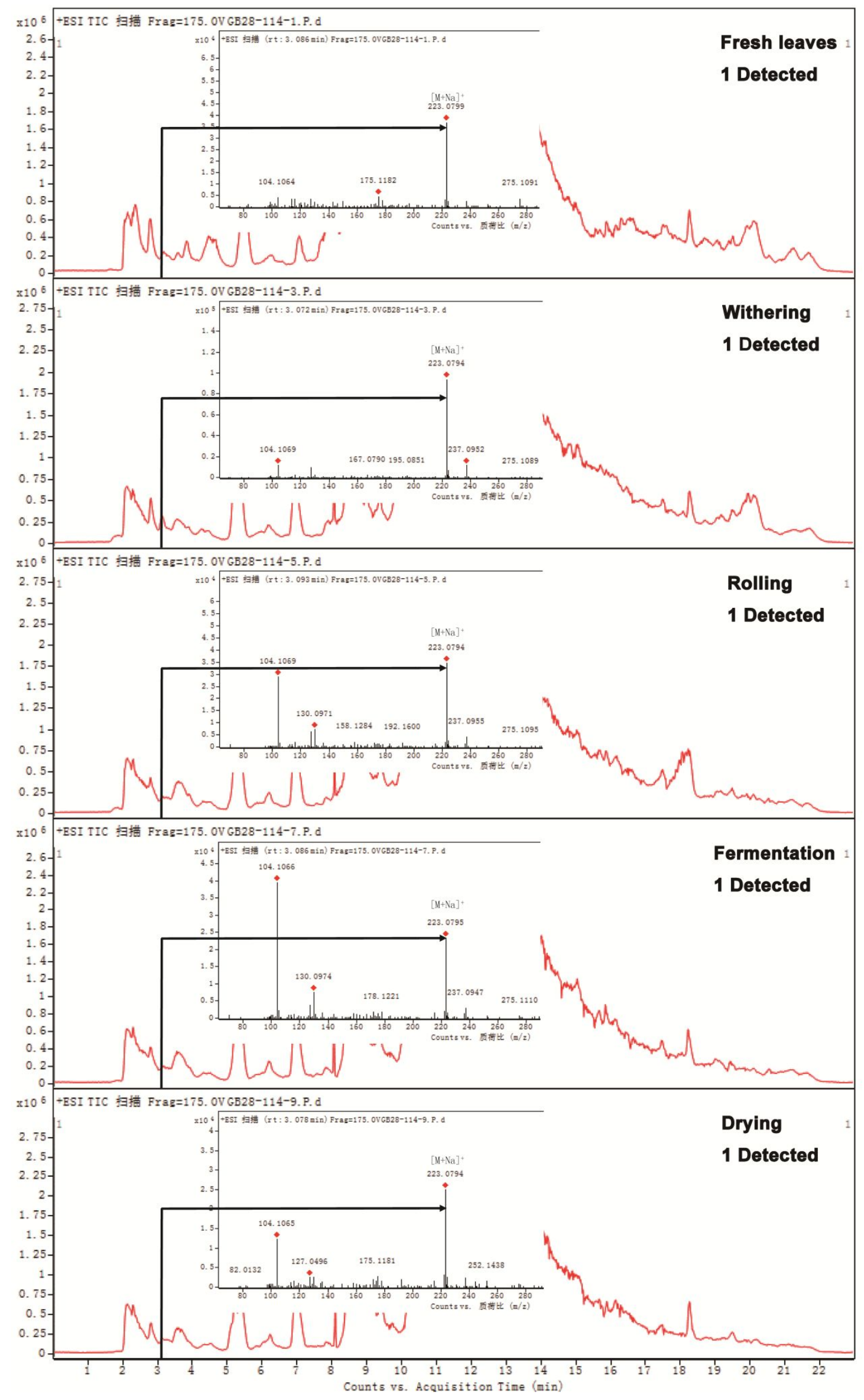

Figure S34. UPLC-TOF-MS analysis of 1 in fresh leaves and the processed materials of Keemun black tea. 


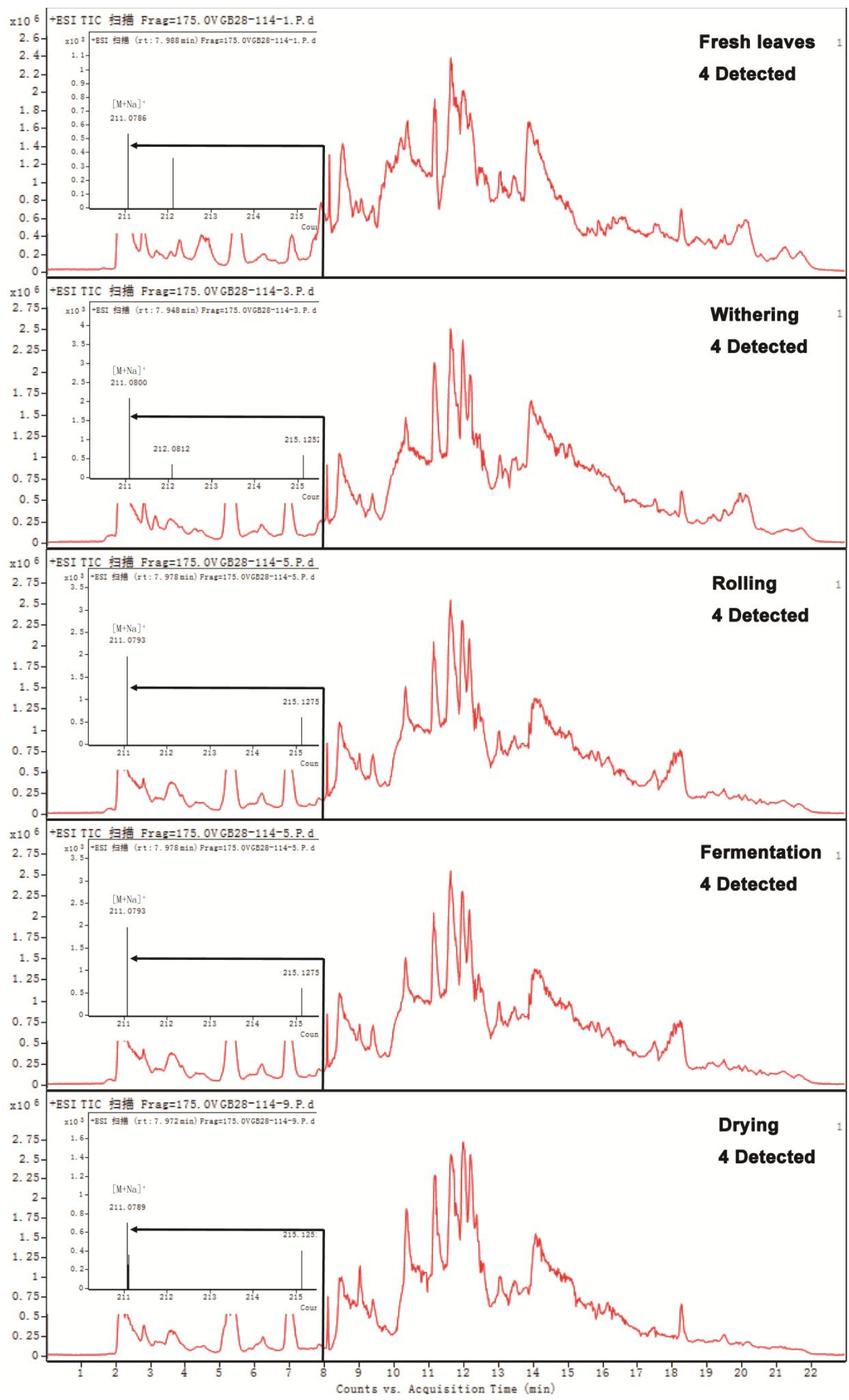

Figure S35. UPLC-TOF-MS analysis of 4 in fresh leaves and the processed materials of Keemun black tea. 


\section{Crystal data and structure refinement for 1-4}

Table S5. Crystal data and structure refinement for $\mathbf{1}$

\begin{tabular}{|c|c|}
\hline Identification code & $\mathrm{gb} 28-91-1$ \\
\hline Empirical formula & $\mathrm{C}_{7} \mathrm{H}_{14} \mathrm{~N}_{4} \mathrm{O}_{4}$ \\
\hline Formula weight & 218.22 \\
\hline Temperature/K & 291(2) \\
\hline Crystal system & orthorhombic \\
\hline Space group & Pbca \\
\hline $\mathrm{a} / \AA$ & $7.8263(4)$ \\
\hline $\mathrm{b} / \AA$ & $12.3754(6)$ \\
\hline c/ $\AA$ & $21.7965(10)$ \\
\hline$\alpha /^{\circ}$ & 90 \\
\hline$\beta /{ }^{\circ}$ & 90 \\
\hline$\gamma /{ }^{\circ}$ & 90 \\
\hline Volume/ $\AA^{3}$ & $2111.07(18)$ \\
\hline $\mathrm{Z}$ & 8 \\
\hline$\rho_{\text {calc }} \mathrm{g} / \mathrm{cm} 3$ & 1.373 \\
\hline$\mu / \mathrm{mm}^{-1}$ & 0.965 \\
\hline $\mathrm{F}(000)$ & 928.0 \\
\hline Crystal size $/ \mathrm{mm}^{3}$ & $0.240 \times 0.220 \times 0.210$ \\
\hline Radiation & $\mathrm{CuK} \alpha(\lambda=1.54184)$ \\
\hline $2^{\Theta}$ range for data collection ${ }^{\circ}$ & 8.112 to 142.144 \\
\hline Index ranges & $-9<=\mathrm{h}<=6,-14<=\mathrm{k}<=12,-26<=1<=23$ \\
\hline Reflections collected & 6476 \\
\hline Independent reflections & $2008\left[R_{\mathrm{int}}=0.0213, R_{\mathrm{sigma}}=0.0136\right]$ \\
\hline Data/restraints/parameters & $2008 / 0 / 142$ \\
\hline Goodness-of-fit on $\mathrm{F}^{2}$ & 1.020 \\
\hline Final $\mathrm{R}$ indexes $[\mathrm{I}>=2 \sigma(\mathrm{I})]$ & $\mathrm{R}_{1}=0.0607, \mathrm{wR}_{2}=0.1652$ \\
\hline Final $\mathrm{R}$ indexes [all data] & $\mathrm{R}_{1}=0.0670, \mathrm{wR}_{2}=0.1698$ \\
\hline Largest diff. peak/hole / e $\AA^{-3}$ & $0.41 /-0.32$ \\
\hline
\end{tabular}


Table S6. Crystal data and structure refinement for $\mathbf{2}$

\begin{tabular}{|c|c|}
\hline Identification code & $\mathrm{gb} 28-90-4$ \\
\hline Empirical formula & $\mathrm{C}_{14} \mathrm{H}_{24} \mathrm{~N}_{8} \mathrm{O}_{7}$ \\
\hline Formula weight & 416.41 \\
\hline Temperature/K & 291(2) \\
\hline Crystal system & monoclinic \\
\hline Space group & $\mathrm{C} 2 / \mathrm{c}$ \\
\hline $\mathrm{a} / \AA$ & $16.1101(2)$ \\
\hline $\mathrm{b} / \AA$ & $7.32740(10)$ \\
\hline $\mathrm{c} / \AA$ & $16.4059(2)$ \\
\hline$\alpha /^{\circ}$ & 90 \\
\hline$\beta /{ }^{\circ}$ & $101.5500(10)$ \\
\hline$\gamma /{ }^{\circ}$ & 90 \\
\hline Volume/ $\AA^{3}$ & $1897.42(4)$ \\
\hline $\mathrm{Z}$ & 4 \\
\hline$\rho_{\text {calc }} \mathrm{g} / \mathrm{cm} 3$ & 1.458 \\
\hline$\mu / \mathrm{mm}^{-1}$ & 1.009 \\
\hline $\mathrm{F}(000)$ & 880.0 \\
\hline Crystal size $/ \mathrm{mm}^{3}$ & $0.220 \times 0.210 \times 0.210$ \\
\hline Radiation & $\operatorname{CuK} \alpha(\lambda=1.54184)$ \\
\hline $2^{\Theta}$ range for data collection ${ }^{\circ}$ & 11.008 to 142.24 \\
\hline Index ranges & $-14<=\mathrm{h}<=19,-8<=\mathrm{k}<=8,-19<=\mathrm{l}<=19$ \\
\hline Reflections collected & 5754 \\
\hline Independent reflections & $1799\left[R_{\mathrm{int}}=0.0124, R_{\mathrm{sigma}}=0.0088\right]$ \\
\hline Data/restraints/parameters & $1799 / 0 / 139$ \\
\hline Goodness-of-fit on $\mathrm{F}^{2}$ & 1.062 \\
\hline Final $\mathrm{R}$ indexes $[\mathrm{I}>=2 \sigma(\mathrm{I})]$ & $\mathrm{R}_{1}=0.0428, \mathrm{wR}_{2}=0.1204$ \\
\hline Final $\mathrm{R}$ indexes [all data] & $\mathrm{R}_{1}=0.0437, \mathrm{wR}_{2}=0.1211$ \\
\hline Largest diff. peak/hole / e $\AA^{-3}$ & $0.32 /-0.36$ \\
\hline
\end{tabular}


Table S7. Crystal data and structure refinement for $\mathbf{3}$

\begin{tabular}{|c|c|}
\hline Identification code & GB28-8902 \\
\hline Empirical formula & $\mathrm{C}_{14} \mathrm{H}_{22} \mathrm{~N}_{8} \mathrm{O}_{6}$ \\
\hline Formula weight & 398.39 \\
\hline Temperature/K & 291(2) \\
\hline Crystal system & triclinic \\
\hline Space group & P-1 \\
\hline $\mathrm{a} / \AA$ & $12.8058(5)$ \\
\hline $\mathrm{b} / \AA$ & $13.2235(5)$ \\
\hline $\mathrm{c} / \AA$ & $13.5118(5)$ \\
\hline$\alpha /^{\circ}$ & $64.581(4)$ \\
\hline$\beta /{ }^{\circ}$ & $70.424(4)$ \\
\hline$\gamma /{ }^{\circ}$ & $86.273(3)$ \\
\hline Volume/ $\AA^{3}$ & $1938.74(15)$ \\
\hline $\mathrm{Z}$ & 4 \\
\hline$\rho_{\text {calc }} \mathrm{g} / \mathrm{cm} 3$ & 1.365 \\
\hline$\mu / \mathrm{mm}^{-1}$ & 0.925 \\
\hline $\mathrm{F}(000)$ & 840.0 \\
\hline Crystal size $/ \mathrm{mm}^{3}$ & $0.250 \times 0.200 \times 0.180$ \\
\hline Radiation & $\operatorname{CuK} \alpha(\lambda=1.54184)$ \\
\hline $2^{\Theta}$ range for data collection ${ }^{\circ}$ & 7.358 to 142.828 \\
\hline Index ranges & $-15<=\mathrm{h}<=15,-16<=\mathrm{k}<=12,-16<=\mathrm{l}<=16$ \\
\hline Reflections collected & 13328 \\
\hline Independent reflections & $7310\left[R_{\mathrm{int}}=0.0267, R_{\mathrm{sigma}}=0.0323\right]$ \\
\hline Data/restraints/parameters & $7310 / 0 / 517$ \\
\hline Goodness-of-fit on $\mathrm{F}^{2}$ & 1.051 \\
\hline Final $R$ indexes $[\mathrm{I}>=2 \sigma(\mathrm{I})]$ & $\mathrm{R}_{1}=0.0496, \mathrm{wR}_{2}=0.1418$ \\
\hline Final $R$ indexes [all data] & $\mathrm{R}_{1}=0.0555, \mathrm{wR}_{2}=0.1479$ \\
\hline Largest diff. peak/hole / e $\AA^{-3}$ & $0.26 /-0.26$ \\
\hline
\end{tabular}


Table S8. Crystal data and structure refinement for 4

\begin{tabular}{ll}
\hline Identification code & $\mathrm{Gb} 11-105-4$ \\
\hline Empirical formula & $\mathrm{C}_{6} \mathrm{H}_{12} \mathrm{~N}_{4} \mathrm{O}_{3}$ \\
Formula weight & 188.20 \\
Temperature/K & $290(2)$ \\
Crystal system & orthorhombic \\
Space group & $\mathrm{Pbcn}$ \\
$\mathrm{a} / \AA$ & $13.018(5)$ \\
$\mathrm{b} / \AA$ & $7.566(5)$ \\
$\mathrm{c} / \AA$ & $17.867(5)$ \\
$\alpha /{ }^{\circ}$ & $90.000(5)$ \\
$\beta /{ }^{\circ}$ & $90.000(5)$ \\
$\gamma /{ }^{\circ}$ & $90.000(5)$ \\
Volume/ $\AA^{3}$ & $1759.8(14)$ \\
$\mathrm{Z}$ & 8 \\
$\rho_{\text {calc }} \mathrm{g} / \mathrm{cm} 3$ & 1.421 \\
$\mu / \mathrm{mm}^{-1}$ & 0.115 \\
$\mathrm{~F}(000)$ & 800.0 \\
Crystal size/mm & \\
Radiation & $0.420 \times 0.320 \times 0.310$ \\
$2^{\Theta}$ range for data collection/ & \\
Index ranges & $\mathrm{MoK} \alpha(\lambda=0.71073)$ \\
Reflections collected & $-15<=\mathrm{h}<=15,-9<=\mathrm{k}<=7,-21<=1<=21$ \\
Independent reflections & 11158 \\
Data/restraints/parameters & $1630\left[R_{\text {int }}=0.0207, R_{\text {sigma }}=0.0116\right]$ \\
Goodness-of-fit on $\mathrm{F}^{2}$ & $1630 / 0 / 133$ \\
Final R indexes [I $>=2 \sigma(\mathrm{I})]$ & 1.082 \\
Final R indexes [all data] & $\mathrm{R}_{1}=0.0389, \mathrm{wR}_{2}=0.1155$ \\
Largest diff. peak/hole / e $\AA^{-3}$ & $\mathrm{R}_{1}=0.0410, \mathrm{wR}_{2}=0.1185$ \\
\hline
\end{tabular}

X-ray crystallographic data for 1-4 are available from the Cambridge Crystallographic Data Centre (CCDC 1910039 for 1, CCDC 1910040 for 2, CCDC 1910041 for $\mathbf{3}$ and CCDC 1910042 for 4).

\section{References}

(1) Wang W.; Tang X.; Hua F.; Ling T. J.; Wan X. C.; Bao G. H. Org. Lett. 2018, 20, 2672-2675.

(2) Ito E.; Ashihara H. J. Plant Physiol. 1999, 154, 145-151.

(3) Frisch, M. J.; Trucks, G. W.; Schlegel, H. B.; Scuseria, G. E.; Robb, M. A.; Cheeseman, J. R.; Scalmani, G.; Barone, V.; Mennucci, B.; Petersson, G. A.; Nakatsuji, H.; Caricato, M.; Li, X.; Hratchian, H. P.; Izmaylov, A. F.; Bloino, J.; Zheng, G.; Sonnenberg, J. L.; Hada, M.; Ehara, M.; Toyota, K.; Fukuda, R.; Hasegawa, J.; Ishida, M.; Nakajima, T.; Honda, Y.; Kitao, O.; Nakai, H.; Vreven, T.; Montgomery, Jr., J. A.; Peralta, J. E.; Ogliaro, F.; Bearpark, M.; Heyd, J. J.; Brothers, E.; Kudin, K. N.; Staroverov, V. N.; Kobayashi, R.; Normand, J.; Raghavachari, K.; Rendell, A.; Burant, J. C.; Iyengar, S. S.; Tomasi, J.; Cossi, M.; Rega, N.; Millam, J. M.; Klene, M.; Knox, J. E.; Cross, J. B.; Bakken, V.; Adamo, C.; Jaramillo, J.; Gomperts, R.; Stratmann, R. E.; 
Yazyev, O.; Austin, A. J.; Cammi, R.; Pomelli, C.; Ochterski, J. W.; Martin, R. L.; Morokuma, K.; Zakrzewski, V. G.; Voth, G. A.; Salvador, P.; Dannenberg, J. J.; Dapprich, S.; Daniels, A. D.; Farkas, Ö.; Foresman, J. B.; Ortiz, J. V.; Cioslowski, J.; Fox, D. J.Gaussian 09, Rev. C 01; Gaussian, Inc., Wallingford CT, 2009.

(4) Stephens, P. J.; Harada, N. ECD cotton effect approximated by the Gaussian curve and other methods. Chirality. 2010, 22, 229-233. 